\title{
Drug and bioactive molecule screening based on a bioelectrical impedance cell culture platform
}

This article was published in the following Dove Press journal: International Journal of Nanomedicine

10 December 2014

Number of times this article has been viewed

\author{
Sakthivel Ramasamy' \\ Devasier Bennet' \\ Sanghyo Kim ${ }^{1,2}$ \\ 'Department of Bionanotechnology, \\ Gachon University, Gyeonggi-Do, \\ Republic of Korea; ${ }^{2}$ Graduate \\ Gachon Medical Research Institute, \\ Gil Medical Center, Incheon, \\ Republic of Korea
}

\begin{abstract}
This review will present a brief discussion on the recent advancements of bioelectrical impedance cell-based biosensors, especially the electric cell-substrate impedance sensing (ECIS) system for screening of various bioactive molecules. The different technical integrations of various chip types, working principles, measurement systems, and applications for drug targeting of molecules in cells are highlighted in this paper. Screening of bioactive molecules based on electric cell-substrate impedance sensing is a trial-and-error process toward the development of therapeutically active agents for drug discovery and therapeutics. In general, bioactive molecule screening can be used to identify active molecular targets for various diseases and toxicity at the cellular level with nanoscale resolution. In the innovation and screening of new drugs or bioactive molecules, the activeness, the efficacy of the compound, and safety in biological systems are the main concerns on which determination of drug candidates is based. Further, drug discovery and screening of compounds are often performed in cell-based test systems in order to reduce costs and save time. Moreover, this system can provide more relevant results in in vivo studies, as well as high-throughput drug screening for various diseases during the early stages of drug discovery. Recently, MEMS technologies and integration with image detection techniques have been employed successfully. These new technologies and their possible ongoing transformations are addressed. Select reports are outlined, and not all the work that has been performed in the field of drug screening and development is covered.
\end{abstract}

Keywords: screening of bioactive agents, impedance-based cell study, electric cell-substrate impedance sensing (ECIS), high-throughput screening, real-time drug evaluation

\section{Introduction}

Intensive research on the development of new drugs for safer therapeutic interventions for various diseases, based on scientific advancements in high-throughput screening (HTS), has so far resulted in the development of synthetic, semisynthetic, and natural compounds. The bioimpedance method has proved to be an ideal technique for whole cellular behavior detection without radioactive or fluorescence-labeled substrates to quantify cell morphology changes. Following this development, Giaever and Keese developed electric cell-substrate impedance sensing (ECIS) as a continuous monitoring system for studying cell behaviors using a noninvasive, real-time, and label-free method. ${ }^{1}$ Since then, research groups have developed various technical upgrades for different screening applications. Bioelectrical impedance cell culture platforms are capable of analyzing all cellular events, including cell attachment, spreading, migration, growth, mitosis, cell-cell contacts behavior, cell-matrix contacts behavior, and death of adhering cells, in a quantitative manner. ${ }^{2-4}$

ECIS has several benefits over other cell-based biosensing methods, in areas including analysis of cell behavior under flow, metastatic potential, and endothelial barrier functions, and toxicological and pharmacological drug screening. Among
Correspondence: Sanghyo Kim

Department of Bionanotechnology, Gachon University, San 65, Bokjeong-

Dong, Sujeong-Gu, Seongnam-Si,

Gyeonggi-Do 46I-70I, Republic of Korea

Tel +82317508554

Fax +82317508819

Email samkim@gachon.ac.kr 
bioelectrical impedance cell culture platforms, ECIS has been recognized as a powerful tool that provides great sensitivity in monitoring cell behavior changes in response to external/environmental conditions, such as $\mathrm{pH}$, temperature, light, and chemical/biological substances. The ECIS system can monitor the impedance signal changes that occur due to electric current between the cells and electrodes and has the capability to detect, analyze, and aid investigation of the effects of bioactive and inactive compounds on cells. The output signal changes can provide statistical values for behaviors of the cell on each electrode, which result from cellular changes caused by external stimuli such as chemical compounds, drugs and or any analytes. Compared to other statistical data measurement systems, ECIS has the greatest potential in drug discovery and screening of new drugs for new diseases and disorders. Great advances have been made in recent decades in the areas of drug discovery and screening, with numerous upgrades to bioimpedance platforms and much innovation in techniques. As a result, treatment efficacy and quality of life have improved.

A hybrid bioimpedance system that uses microfluidic channels has recently emerged. This system is capable of measuring living biological (adherent or nonadherent) cells as an in vitro model for studying the cellular behavior changes caused by external and internal stimuli..$^{5,6}$ Various cellular events, such as cell adherence, spreading, growth, and motility, and various cellular activities, such as signal transduction, amplification, and analyte recognition, are the principal factors involved in identification of toxins and screening of bioactive molecules or drugs. This system offers possible new directions for biomedical and therapeutic applications such as new drug evaluation, testing, and screening as well as toxin identification for various diseases, including various forms of oxidative stress-induced damage., ${ }^{2,7}$ This platform can provide quantitative and qualitative measurement with real-time optical imaging, and, importantly, it can mimic in vivo biophysical responses, which will give a response similar to the in vivo expression. This system has many advantages: rapidity, enhance sensitivity, bio-recognition on-the-spot and earlystage detection, and targeting are important features of this system. In brief, it can detect any forms of substances, including chemicals, microorganisms, and environmental toxins, because the cell periphery has different types of receptors which can produce different responses for different substances. Because of these important features, ECIS is recognized as a unique and reliable way to determine the physiological characters of living cells. ${ }^{3}$
This review focuses on identification of various bioactive therapeutic molecules and screening for various diseases during various cellular events using ECIS. Furthermore, this review will provide enriched information about ECIS-based tools for bioactive molecule screening and drug development.

\section{Electrical resistance and impedance measurements with ECIS}

ECIS is an advanced system that is based on the principles of bioimpedance and that uses alternating current (AC) to evaluate cellular behavior in physiological conditions. A typical working principle of the ECIS system is shown in Figure 1A and 1B. Some of the typical ECIS electrode array types, which are used in different assays for cell study, are shown in Figure 1C.

The structural design of the ECIS system comprises two electrodes: one is a small working electrode and the other a large counter electrode on the bottom of the culture plate. The electrodes are connected to the edge of a culture chip; the chip is connected to the lock-in amplifier, and the whole setup is kept inside an incubator at $37^{\circ} \mathrm{C}$ and under a $5 \% \mathrm{CO}_{2}$ atmosphere. The lock-in amplifier is connected to a personal computer for data acquisition, storage, and interpretation. After cell seeding, cells drift downward and attach to the stratum of the electrode, which then passes the impeded current directly into the bulk electrolyte as the result of anchored plasma membrane intrusion above the electrode surface. ${ }^{1}$ Basically, the cell membranes have insulating properties, so the cells are attached to the working electrode and impede the electric flow between the electrodes. This represents the passage of current through the available cell substrate space as well as between available intercellular junctions. This can result in changes in impedance, and the rate of changes of the impedance increases until the cells reach confluent on electrode. Initially, resistance increases due to attachment and spreading, followed by confluence, of the cells, and the changes in impedance are measured. The changes in electrical impedance of this real-time system are a function of AC frequency, and the resulting voltage and resistance are measured with a lock-in amplifier. This resulting impedance is monitored every second at various suitable preset frequencies $(1-100 \mathrm{kHz})$, and data collection and processing are carried out with suitable software. The impedance measurement is noninvasive. ${ }^{8,9}$ Figure 2 shows the various cellular events during cell culture in the ECIS system. Variation in cell behavior after cell attachment, spreading, proliferation, micromotion, demise, and/or responses to external substances result in changes in impedance. ${ }^{10}$ 


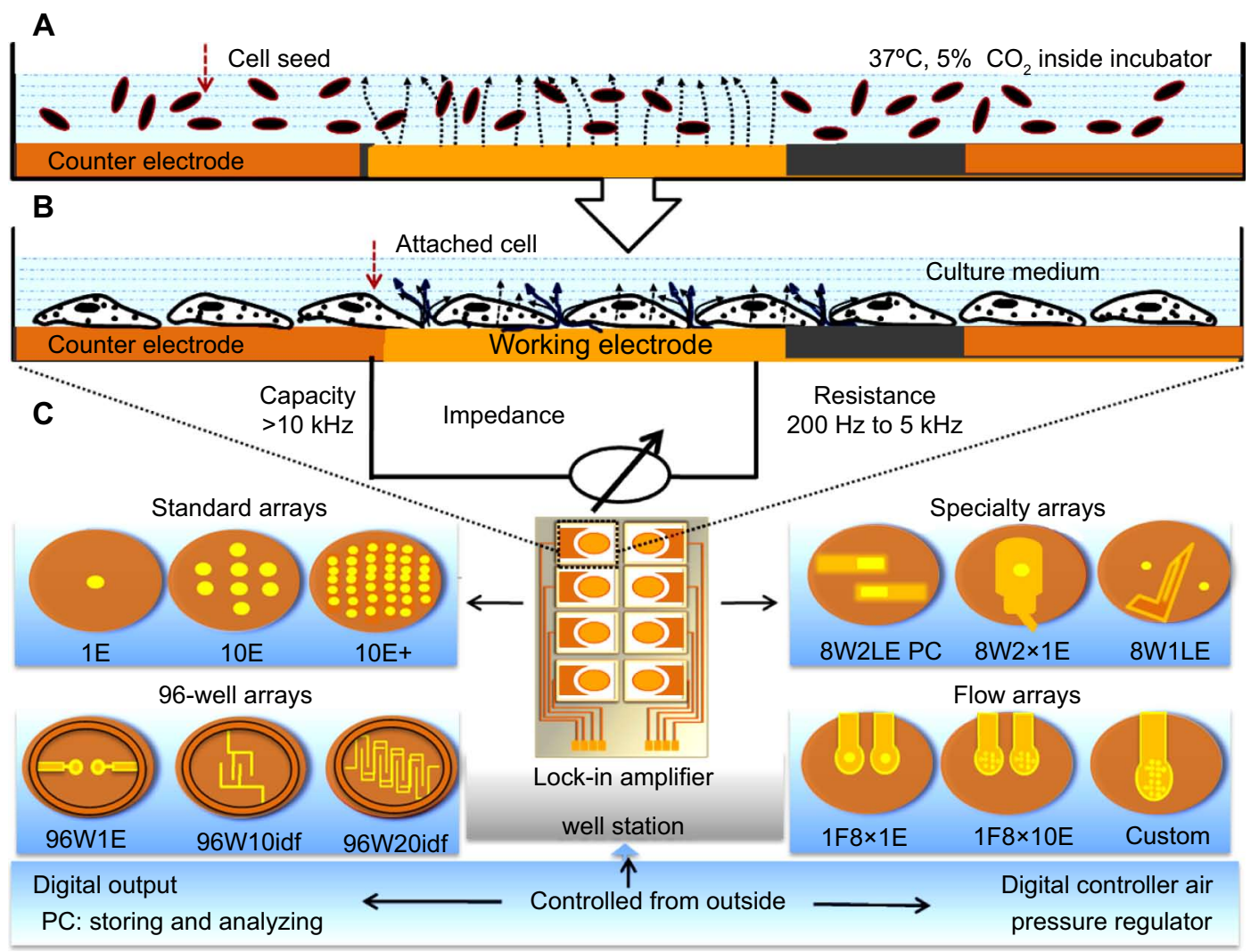

Figure I Schematic diagram of the ECIS method working principle.

Notes: (A) Current flow before cell attachment. (B) After cell attachment, the current flows with cells from the surface of Au-sensing electrodes. Cells are grown to confluence on electrodes. The current flow between working electrodes and counter electrodes through cell culture medium, which acted as electrolyte. (C) Different types of ECIS electrode arrays for various applications.

Abbreviations: ECIS, electric cell-substrate impedance sensing; W, well; E, electrode; idf, inter-digitated finger configuration; LE, linear electrode; F, flow array; E+, addition of more electrodes; LE, linear electrode; PC, polycarbonate substrate.

To elucidate impedance date, several researchers have derived calculations for quantifying cell parameters, including impedance changes and cell population via different mathematical models. Using least squares optimization,

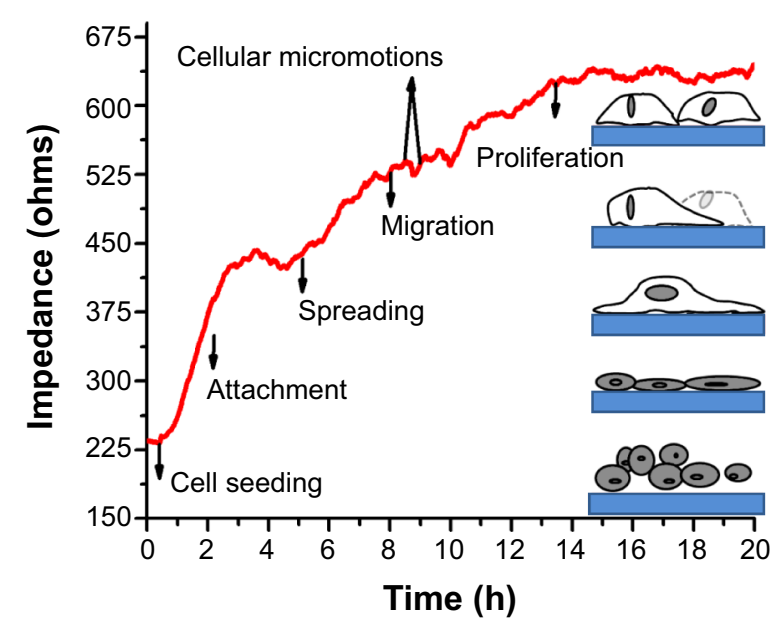

Figure 2 A typical electric cell-substrate impedance sensing (ECIS) measurement graph of normal HDFn cell growth response for 20 hours, showing various cellular morphological changes.

Abbreviation: HDFn, human dermal fibroblasts, neonatal cells.
Giaever and Keese derived a mathematical approximation for the total impedance of cells covering the electrode, as illustrated by Equation 1:

$$
Z_{\text {total }}=\frac{1}{z_{n}}\left(\frac{Z_{n}}{Z_{n}+Z_{m}}+\frac{\frac{Z_{m}}{Z_{n}+Z_{m}}}{\left(\frac{i \gamma_{c}}{2}\right)\left(\frac{I_{0} \gamma_{c}}{I_{1} r_{c}}\right)+2 R_{b}\left(\frac{1}{z_{n}}+\frac{1}{z_{m}}\right)}\right)
$$

where $I_{0}$ and $I_{1}$ are the modified Bessel functions, $R_{b}$ the resistance between the cells, $r_{c}$ the cellular radius, $Z_{n}$ the impedance of the cell-free electrode, and $Z_{m}$ the impedance of the plasma membrane. $Z_{m}$ is determined based on membrane capacity $\left(Z_{m}=2 / i \omega \mathrm{Cm}\right)$, while $\gamma$ is described by Equation 2:

$$
\gamma r_{c}=r_{c} \sqrt{\frac{\rho}{h}\left(\frac{1}{z_{n}}+\frac{1}{z_{m}}\right)}
$$


In Equation 2, $\rho / h$ accounts for the impedance arising in the adhesion zone between cells and substrate, the resistivity of the electrolyte beneath the cell $\rho$, and the space between the membrane and electrode surface $h$; this approximation was made using electric equivalent circuits. ${ }^{11}$ Later, constant phase elements were introduced to enable more sensitive measurement. The measurement of capacitance shows that higher frequencies are most suited for cell spreading because they increase cell coverage of the electrode. At high frequency ranges, measurement is more sensitive to changes in cell attachment and spreading at the electrode. However, $10-40 \mathrm{kHz}$ is the main frequency range used for measuring impedance. ${ }^{12}$

\section{Recent progress and developments in ECIS}

In most of the ECIS based studies, the large-sized integrated microelectrode array platforms has been utilized, this system can provide data for the combined physical responses of cells. The ECIS system has been developed based on various approaches and methods used to evaluate the cellular properties, including microelectrode array chip pattern, positioning, sensing device, and flow. Some cell-based biosensing chip fabrication designs are depicted in Figure 3.

Recently, Xu et al and Tran et al developed an integrated device with microfluidic channels to prevent unwanted flow based on a hydrogel-based diffusion cell chip to produce a gradient concentration with prolonged stability for highthroughput assays. ${ }^{5,6}$ In the interests of continuous development, the ECIS platform was integrated with microfluidic system allows laminar flow, which provides meaningful information for HTS. ${ }^{13,14}$ This system can provide gradients of diffusion, ${ }^{15,16}$ but is not compatible with all samples. For further continuous development, pneumatic microvalves, air-bubble valves, ${ }^{17}$ and thermopneumatic gas-bubble microvalves for temperature control ${ }^{18}$ were integrated into the microfluidic chips to control the flow. Study of complex and simultaneous cellular responses to various substances using HTS platforms has been improved by the integration of a hydrogel-based diffusion microfluidic channel chip. To achieve further continuous development of cell-based biosensing and drug screening techniques, researchers developed two- and three-dimensional microfluidic-based gradient generators for HTS, which can provide a synergistic effect for combined administration of multiple-drug doses. ${ }^{15,19}$ A system for single-cell analysis using cell impedance monitoring has been recently developed. This system can provide fine detectability on individual electrodes, compared to many cells on a large-sized electrode, and has potential in environmental toxin identification and drug estimation. ${ }^{20}$ This single-cell analytical system enables more precise estimation of the cellular response to ion channel-regulating drugs. The real-time optical imaging and

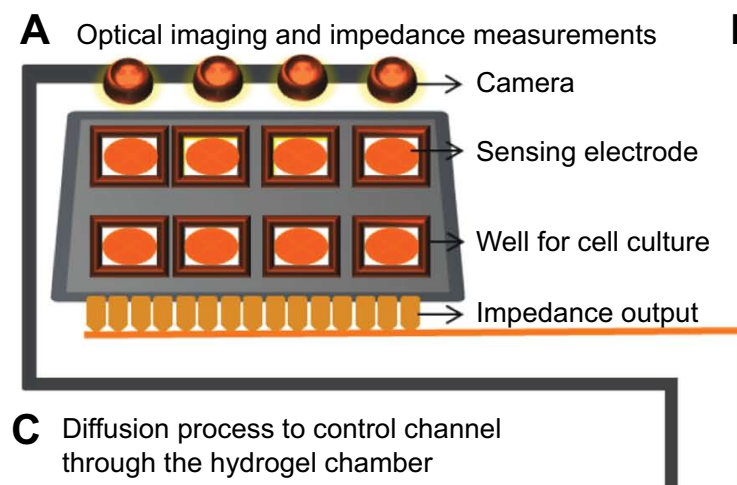

B Microfluidic device with passive air-bubble valves

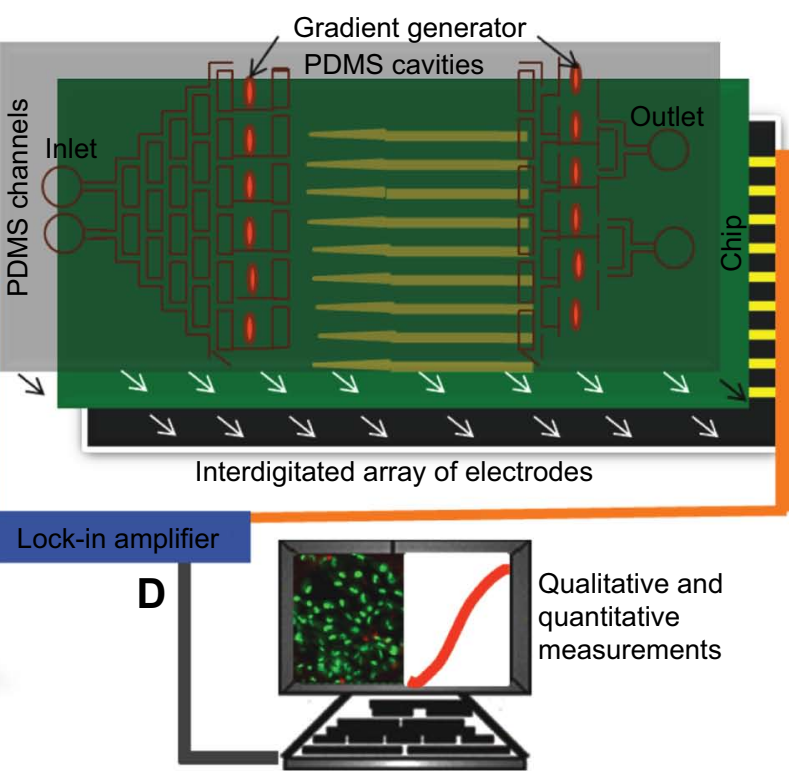

Figure 3 Schematic diagram showing various devices and microelectrode chip fabrication types for different studies using bioimpedance platform.

Notes: (A) Real-time optical imaging and impedance measurements. The camera is located above the cell culture chip, which enables provision of real-time imaging. (B) Microfluidic based cell culture sensing system: interdigitated array of electrodes on glass for impedance sensing, a polydimethylsiloxane (PDMS) layer for gradient generation and cell culture, which can provide the concentration dependent cellular behavior. (C) Three-dimensional depiction of a hydrogel chamber of a diffusion cell culture chip integrated with electric cell-substrate impedance sensing (ECIS). (D) Qualitative and quantitative data acquisition using a computer interface with a data monitoring and storage system. 
impedance measurements are perhaps better for qualitative and quantitative studies. The gold electrode has been shown to be a safe, nontoxic, and nonreactive material for use as a bioimpedance sensor chip; however, for certain analyses, a custom-made specific array could be a better choice.

\section{Real-time HTS of drugs without labeling}

HTS is an important method in drug discovery, as it allows rapid pharmacological testing of various chemical compounds in order that safe, nontoxic, and maximally tolerated drugs with no adverse side effects to normal cell activities can be developed. ${ }^{21}$ Real-time, label-free, rapid-assessment methodology has been used Real-time, label-free, continuous, rapid assessment methodology has been used used for highthroughput primary drug screening and evaluation, which provides desirable evidence of cellular behavior. Quantitative impedance measurement has been successfully applied to a variety of cell types using different kinds of chemicals, therapeutic compounds, and nanoparticles, including polymer, metal, and metal oxide nanoparticles. The drug screening test is used to find out the various effects of a drug prior in the development of effective treatment for various health problems. This system can be used in various cellular assays, including cytotoxicity, wound-healing, anticancer, antiviral, protectivity, migration, and barrier-disruptive assays, as well as assays for many other cellular activities. Examples of its application in cellular assays are shown in Figure 4. For the evaluation of health-related problems, we are pointing out some examples of health risk effects at the molecular level of analysis; in particular, chemokine attraction occurs during chronic inflammation upon binding of adhesion molecules from leukocytes to the activated endothelium.

In therapeutics, it is important to identify suitable compounds with the ability to control the interaction between leukocytes and endothelial compartments. In drug screening, side effects such as cytotoxicity and barrier-disruptive activities must be elucidated. ECIS is employed to determine monolayer integrity as well as the viability of human lung microvascular endothelial cells (HL-MVECs) in the presence of bioactive cyanobacterial compounds. If the cells are exposed to high (toxic-level) concentrations of chemical compounds, the impedance values decrease due to the total cell mortality, but, with lower concentrations of chemical compounds, the impedance values increase due to cell survival. In one study, the cell impedance changed in a dosedependent manner with different concentrations of Triton $\mathrm{X}-100$. Cyanobacterial compounds applied to HL-MVEC monolayers supported barrier integrity when compared with the control. These results suggest that cyanobacterial compounds can reduce ICAM-1 and IL-8 levels in TNFactivated HL-MVECs by abrogating endothelial monolayer disruption. ${ }^{22}$ This system provides theoretical insights into toxin detection to determine the level of toxicity. Michael et al investigated the activation of receptor A-disintegrin and metalloprotease 10 (ADAM10) during cytotoxin-mediated endothelial injury caused by Staphylococcus aureus. Staphylococcal alpha-hemolysin (Hla) and its effects on endothelial barrier function were measured by ECIS. Resistance of human pulmonary artery endothelial cell monolayers was recorded until a constant resistance of approximately 600 $1,000 \Omega$ before the addition of the purified toxins. In human pulmonary artery endothelial cell monolayers, Hla at a $75 \mathrm{nM}$ concentration resulted in a quick and dynamic decrease in resistance, as well as $\mathrm{Hla}$ at $30 \mathrm{nM}$ concentration altered monolayer resistance. Knockdown of ADAM10 prevented toxin-induced loss of endothelial barrier function. ${ }^{23}$

The cell-based assays are frequently used for drug discovery using HTS; one such method includes ECIS, which is a multi-parameter detection method, leading to better prediction of results and better understanding of cellular events, external chemical compounds, and environmental stimuli in an in vitro model, meaning ECIS could be an effective way to study drugs.

\section{ECIS application in drug screening for various interventions General mechanisms and evaluation of ECIS-based toxicity screening}

ECIS-based cell toxicity screening is a successful, rapid, and successful technique for the analysis and identification of cellular events. The output results from the ECIS technique correlated well with other conventional assays and is also considered as an economic and no labor-intensive. Clinically, a wide range of drugs have been used for various interventions; in order to achieve safety and better clinical tolerance, all active drug ingredients have to be screened for cytotoxic side effects. The identification of cytotoxic side effects on body tissues/organs is essential for determining the safety of new active chemical compounds. ECIS-based HTS is well suited for drug assays, and is possibly the best method of in vivo testing of chemical compound/drug toxicity to body tissues/organs. The onset/early stage response of the cell cytoskeletal status and effects of drugs, inhibitors, and chemical compounds can be rapidly screened by measuring the time response functions of cells. ECIS based HTS system can enables to improve high-density well formats, which facilitates to screen large numbers of cell samples at 

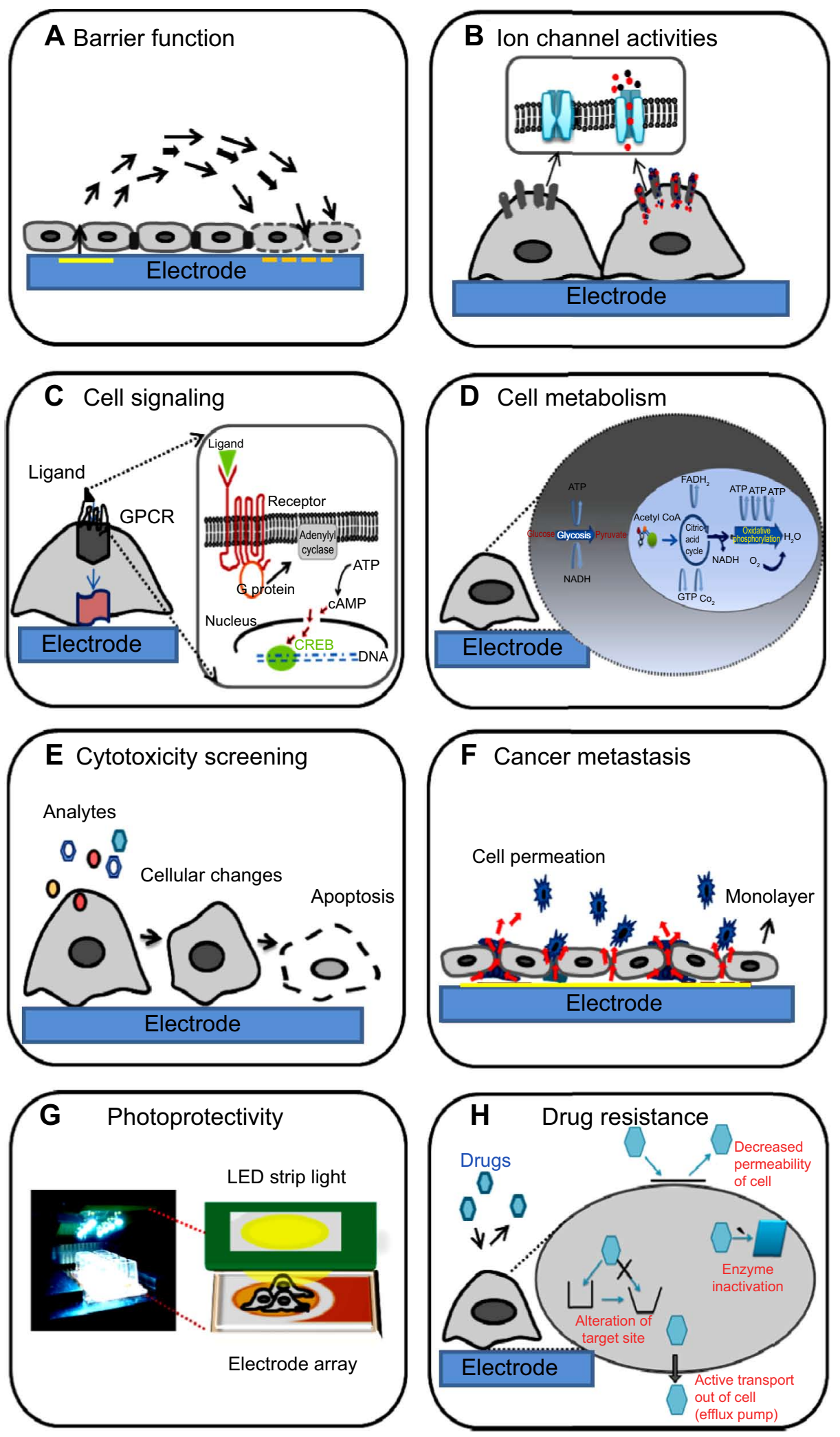

Figure 4 Applications of the ECIS system for analysis of cellular behaviors and activity for drug screening studies.

Notes: (A) Barrier function analysis for paracellular pathway and permeability study. (B) lon channel activity analysis for studying ion transport mechanisms and whether the compound is able to block the channel. (C) Cell signaling analysis for studying cell/extracellular matrix interaction or disruption of signaling pathways. (D) Cell metabolism analysis for studying the differences in growth and metabolic status of cells. (E) Cytotoxicity screening for studying analyte toxicity responses to the cells. (F) Cancer metastasis analysis for studying cancer cell behavior including the potentiality of drugs effects on cells. (G) Photoprotectivity analysis for studying photodamaging and photoprotective effects. $(\mathbf{H})$ Drug resistance analysis for studying drug resistance capacity in various cells, including cancer cells, including cancer cells.

Abbreviations: Acetyl CoA, acetyl coenzyme A; ATP, adenosine triphosphate; ECIS, electric cell-substrate impedance sensing; GPCR, G-protein-coupled receptor. 
the particular time and thereby achieving a high-throughput. This ECIS technique plays an essential role in determination of cytotoxic potential, which is an important part of biomedical and pharmaceutical research. It also has the capability to identify toxic compounds that cause cell damage and death. A simple mathematical model was developed to express the realtime response obtained by ECIS, which are related to adhesion, spreading, and proliferation of cells. After inoculation, cells exposed to different concentration of toxins, depends on the concentration of toxins the cellular resistance has changes. The resistance changes $(\Delta R)$ purely dependent on the concentration of toxicant $(c)$, exposure time $(t)$ and the initial value $\left(Z_{\mathrm{o}}\right)$ number of cells attached on detecting electrodes. ${ }^{24}$ When the cells are exposed to high (toxic-level) concentrations of chemical compounds, the impedance values of time response cell functions will decrease due to the total cell mortality. The changes in resistance normalized by $Z_{o}$ are known as cell response to toxicant, and the equation for the measurement of real-time response of cells to the toxicant is as follows:

$$
f(c, t)=\Delta R_{s} / Z_{o}
$$

The concentration of an inhibitor required to attain 50\% inhibition of the cytotoxic effect, which can provide valuable information about toxicity, is known as the half-inhibitory concentration of the coefficient $\left(E C I S_{50}\right)$ and is determined using the following equation:

$$
f\left(E C I S_{50}, t\right) / f(0, t)=50 \%
$$

Using Equation 4, cell functions in response to different concentrations of a drug can be obtained. The cell response function of $50 \%$ inhibition curves at a particular time are shown

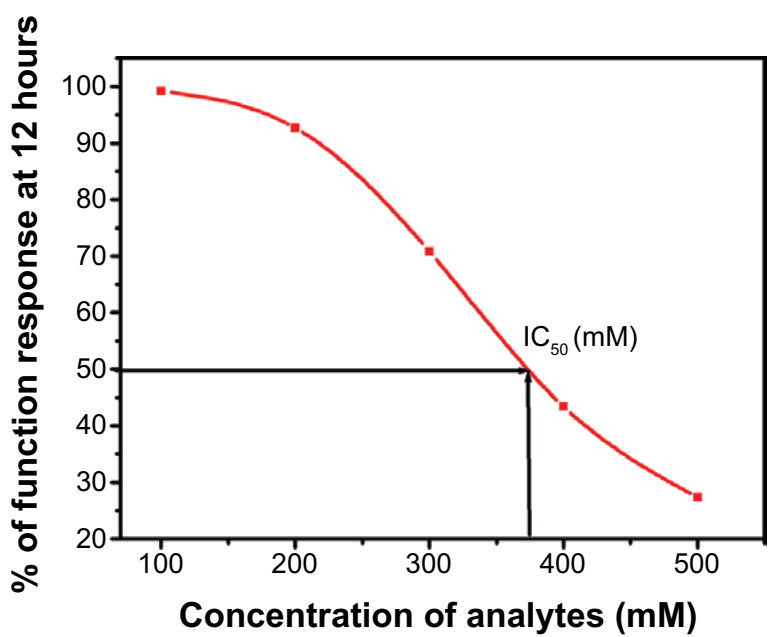

Figure 5 Concentration-response curves for $50 \%$ inhibition effects of cells, which is derived from the impedance profile at 12 hours after various analyte concentration administrations.

Note: Basic graph for the half-inhibition $\left(\mathrm{IC}_{50}\right)$ concentration profile. in Figure 5. The optimum nontoxic concentrations for substance use were examined to show the maximum cell tolerance and half-inhibition activity concentration that is safe and nontoxic for the cells. $E C I S_{50}$ for treatment with drugs at different concentrations was calculated using the simplified Equation 5:

$$
\text { ECIS }_{50}=\left[\frac{Z-Z_{d}}{Z_{c}-Z_{d}}\right] \times 100
$$

where $Z_{d}$ refers to the cellular impedance at a particular time after drug treatment, while $Z_{c}$ refers to the control; no toxicant was added. The calculation was decided by fitting the theoretical model to the experimental data.

\section{Drug cytotoxicity testing}

Various body organ cells have been used in ECIS-based toxicity studies. The types of toxicities in the studies included renal toxicity, hepatotoxicity, pulmonary toxicity, cardiotoxicity, ototoxicity, gastrotoxicity, ocular toxicity, and poisonous effects of both toxic chemicals and various medications, and those preliminary in vivo studies could be replaced with real-time ECIS-based study. Various toxicity studies and their results are summarized in Table 1.

Based on ECIS, various cytotoxicity evaluations have been done so for. Here, we highlighted some specific examples of toxicity studies of recent interesting research; in particular, during drug development programs, pharmacokinetics is of prime concern in the variation of drug concentration over time. During drug evaluation, metabolism and elimination are important issues, because most drug molecules are metabolized and accumulate in the kidneys and cause nephrotoxicity - hence some drug candidates fail in clinical trials. As such, ECIS-based highthroughput toxicity screening of drug candidates is appropriate for early-stage drug development programs. Drug-induced renal toxicity is a complex process, direct toxicity of drugs to renal cells are considered as paramount and these cell exposed higher drug concentration than that in blood due to reabsorption in glomerular filter. The high level toxicity expressed in renal cells, so, those cells have been involved in drug induced renal-toxicity studies, from the study the toxic and antitoxic concentrations of various drugs have been evaluated.

\section{Toxic responses in various analytes}

Using ECIS-based chemical toxicity evaluation, the concentration of toxicants and time-dependent functions of various cells have been studied and established by various researchers. For example, Xiao et al utilized fibroblast v79 cells to measure the toxic effect and minimum inhibitory concentration 
Table I Toxicity effects of different compounds on different cell types

\begin{tabular}{|c|c|c|c|}
\hline Study & Cells used & Compounds tested & Toxic effects \\
\hline \multirow[t]{4}{*}{ Nephrotoxicity } & Renal tubular cells (HK2) & Cisplatin & $\geq 3 \mu \mathrm{M}$ \\
\hline & & Carboplatin & $\geq \mathrm{I} \mathrm{mM}$ \\
\hline & & 5-fluorouracil & $\geq 6 \mathrm{mM}$ \\
\hline & & Cyclophosphamide & $\geq 6 \mathrm{mM}$ \\
\hline \multirow[t]{2}{*}{ Cytotoxicity } & Renal tubular cells (HK2) & Glutathione & $\geq 2 \mathrm{mM}$ \\
\hline & & Sodium thiosulfate & $\geq 0.5 \mathrm{mM}$ \\
\hline \multirow[t]{2}{*}{ Cardiotoxicity } & Cardiomyocytes & Microtubule affinity-regulating & Increased gap formation \\
\hline & & kinase inhibitors & \\
\hline Pulmonary toxicity & Pulmonary endothelial & $\begin{array}{l}12 \text { waterborne industrial } \\
\text { chemicals used }\end{array}$ & Eight chemicals produced toxicity \\
\hline \multirow{6}{*}{$\begin{array}{l}\text { Toxins (neurotoxicity/ } \\
\text { genotoxicity/hepatotoxicity/ } \\
\text { dermatotoxicity) }\end{array}$} & Chinese hamster ovary cells & Cylindrospermopsin, & No effect at $20 \mu \mathrm{g} / \mathrm{mL}$ \\
\hline & & microcystin-LR & No effect up to $\leq 20 \mu \mathrm{g} / \mathrm{mL}$ \\
\hline & Human embryo kidney cells & Cylindrospermopsin, & No significant effect \\
\hline & & microcystin-LR & No significant effect \\
\hline & Sf9 insect cells & Cylindrospermopsin, & No effect at $20 \mu \mathrm{g} / \mathrm{mL}$ \\
\hline & & microcystin-LR & Effect at $3.3 \mu \mathrm{g} / \mathrm{mL}$ \\
\hline \multirow[t]{2}{*}{ Radiation toxicity } & Eye cells & Different-colored lights & Time-dependent effect \\
\hline & Skin cells & Different-colored lights & Time-dependent effect \\
\hline
\end{tabular}

Note: Select applications have been covered and do not represent all the work that has been done in this field.

of various toxicants, such as cadmium chloride, mercury chloride, sodium arsenate, benzalkonium chloride, and trinitrobenzene. Table 2 provides a summary of chemicals used in different studies, and some nanoparticle effects have been noted. The exposure of v79 cells to quantum dots (QDs), metal complexes, and fluorescent gold nanoparticles has also been investigated by a number of researchers, and the inhibition concentration values were in accordance with standard assay reports. In ECIS-based assays, cadmium selenide QDs showed a direct cytotoxic effect and telluride QDs showed significant toxicity, whereas QDs synthesized with indium gallium phosphide and fluorescent gold nanoparticles showed no cytotoxic effects. QDs delivered the desired quantity of drug to target cells and became conjugated with bioactive receptors for target delivery. ${ }^{25}$ Similarly, cellular proliferation and survival effects were investigated with various polymeric nanoparticles. In particular, quercetin-loaded poly(lactic-co-glycolic acid) and hyaluronic acid nanoparticles were studied in L929 cells. The

Table 2 ECIS-based toxicity studies for various compounds and their different perspective uses

\begin{tabular}{|c|c|c|c|c|}
\hline Compounds & Cells used and type of study & $I_{50}$ & Applicability & Reference \\
\hline Mercury chloride & v79 cells - toxicity & $77.5 \mu \mathrm{M}$ & Disinfectant, fungicide & 24 \\
\hline Benzalkonium chloride & v79 cells - toxicity & $14 \mu \mathrm{M}$ & Preservative, antiseptic & 24 \\
\hline Sodium arsenate & v79 cells - toxicity & $50 \mu \mathrm{M}$ & Toxicant, insecticide & 24 \\
\hline Cadmium chloride & v79 cells - toxicity & $4 \mu \mathrm{M}$ & Toxicant (carcinogen ) & 24 \\
\hline \multirow[t]{2}{*}{ Doxorubicin } & Hela cells & $0.6 \mu \mathrm{M}$ & Chemotherapy & 6 \\
\hline & $\mathrm{NIH} 3 \mathrm{~T} 3$ cells & $2.2 \mu \mathrm{M}$ & & \\
\hline \multirow[t]{2}{*}{ 5-fluorouracil } & Hela cells & $72 \mu \mathrm{M}$ & Chemotherapy & 6 \\
\hline & $\mathrm{NIH} 3 \mathrm{~T} 3$ cells & $42 \mu \mathrm{M}$ & & \\
\hline \multicolumn{5}{|c|}{ Cytotoxicity tests of nanoparticles } \\
\hline \multirow[t]{2}{*}{$\mathrm{NH} 2-\mathrm{PEG}$ rods $(\mathrm{p} / \mathrm{mL})$} & MDCK II cells - micromotion & Nontoxic up & No reduction in micromotion & 33 \\
\hline & & to $\sim 1.32 \times 10^{12}$ & - drug delivery & \\
\hline \multirow[t]{2}{*}{$\mathrm{COOH}-\mathrm{PEG}$ rods $(\mathrm{p} / \mathrm{mL})$} & MDCK II cells - micromotion & Nontoxic up & No reduction in micromotion & 33 \\
\hline & & to $1.32 \times 10^{12}$ & - drug delivery & \\
\hline Multi-shell QDs (p/mL) & MDCK II cells - micromotion & $\sim 2 \times 10^{11}$ & Reduction in micromotion & 33 \\
\hline CTAB rods $(\mathrm{p} / \mathrm{mL})$ & MDCK II cells - micromotion & $\sim 1.20 \times 10^{11}$ & Reduction in micromotion & 33 \\
\hline Pure CTAB $(\mu \mathrm{M})$ & MDCK II cells - micromotion & $\sim 6.4$ & Reduction in micromotion & 33 \\
\hline Pure $C d(A c)_{2}(\mu M)$ & MDCK II cells - micromotion & $\sim 4.3$ & Reduction in micromotion & 33 \\
\hline
\end{tabular}

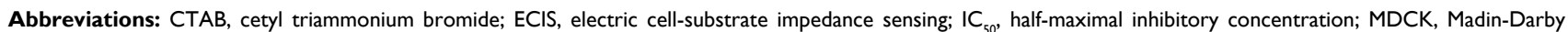
canine kidney; PEG, polyethylene glycol; QDs, quantum dots. 
viability decreased with increased nanoparticle concentration, and the effect of both nanoparticles was concentration- and time-dependent cytotoxicity. Time dependent exposure shows minimum changes after 24 hours, and the cell proliferation rate is highly suppressed in high concentrations due to destruction of cellular properties and also above the ECIS $_{50}$ concentration leads to a cell separation from monolayers. ${ }^{26}$ The variations in cellular behaviors are also important parameters for evaluation of cytotoxicity. Daniel et al examined dose-dependent responses for cytochalasin $\mathrm{B}$ on human umbilical vein endothelial cells (HUVECs) and examine the changes in cell morphology. The fluctuation of impedance indicates that the cytochalasin B causes a decrease of cell-cell resistance, reduction in micromotion, and increase in membrane capacitance at concentrations lower than $0.1 \mu \mathrm{M} .{ }^{27}$

\section{Evaluating toxic responses to environmental risk factors}

For most disease caused by environmental risk factors, including physical, chemical and biological risk factors can also be monitored and evaluated using ECIS. Water contamination and pathogens are the main risk factors for waterborne diseases in humans. Rapid methods for identification of contaminants in water are limited and also require complex instrumentation. Biology-based toxicity sensors provide a quick way to assess unknown compounds. ECIS attains significant information about the presence of different chemicals but it is not suitable for field use. Curtis et $\mathrm{al}^{28}$ developed a field-portable ECIS approach for evaluating the effects of toxicants from 12 waterborne industrial chemicals in various types of mammalian cells. Of the 12 waterborne industrial chemicals, nine were identified in bovine lung microvessel endothelial cell and iguana heart (Igh-2) cell monolayers, and maintain high impedance readings for up to 37 days; which proved a long time cell survival capability. This was a key factor in the development of the field-portable and highly sensitive whole-cell toxicity biosensors, ${ }^{28}$ which revealed that cells can be maintained long term with the use of a compact and self-controlled disposable media delivery system. A curve discrimination model constructed to compare impedance values between control and treated channels on Fluidic biochip confirmed notable differences. Toxicity response results suggested that the fluidic biochips were similar to commercial open-well chips, and the cells are sustained in the chip for at least 9 days using an automated media transport system. This demonstration indicates that the portable bench top system supported both long-term maintenance of cells and data acquisition for impedance measurement from cells after toxic exposure..$^{29}$ Bennet et al, evaluated the continuous light radiation toxicity response on cell using the bioimpedance platform, and they used various light wavelengths, including blue, green, red, and white light radiation. The results revealed that continuous light radiation affects the eye cells.

\section{Cytotoxicity analysis using integrated systems}

The lab-on-chip biosensor-based microfluidic cell culture chip was developed for quick screening of toxic chemicals in potable water, and this system works based on the ECIS principle. After the inoculation of water samples on a fluidic channel cell culture chip, changes in impedance are monitored. Liu et $\mathrm{l}^{30}$ performed rapid screening of water toxicants using an enclosed fluidic biochip, which was a new system comprising the working electrode from ECIS and a quartz crystal microbalance as the top electrode. This combinational method involves two sensors (the quartz crystal microbalance resonator and ECIS for crossverification), and both sensors observe the same cell monolayer and indicate apoptosis caused by toxicants in water. Cell injury caused by toxic water results in reduction of impedance and increased resonant frequency. Bovine aortic endothelial cells were used to sense the cellular responses to toxicants and they are ammonia, nicotine, and aldicarb. This method is sensitive at low concentrations, and the response depends on the types of chemicals and their concentrations. The simultaneous measurement of both corresponding sensor (impedance and mass sensing) was found to boost the accuracy of detection. ${ }^{30}$

Recently, the hydrogel-based diffusion chip was developed for control of unwanted flow. The cell compatibility and ECIS50 were studied for doxorubicin and 5-fluorouracil in Hela and NIH3T3 cells, it can be detect easily in a single test, and hydrogel based diffusion chip provides microfluidic channel, that generates a gradient of concentration with a single injection. The toxicants' ECIS $_{50}$ values were in accordance with other published $\mathrm{IC}_{50}$ values. . $^{6}, 31$

Table 3 provides some examples of drug target identification and screening based on the bioimpedance platform. Thus, ECIS is a promising method for evaluating toxicity compared to other cell-based sensor technologies.

\section{Identification of drug target and affinity-based screening}

In the identification and development of effective and safe therapeutics, the small-molecule have not achieved so far, but identification of small-molecule drug targets and screening has been achieved using label-free cell-based bioaffinity analysis. This biophysical technique can measure the interactions (physical 


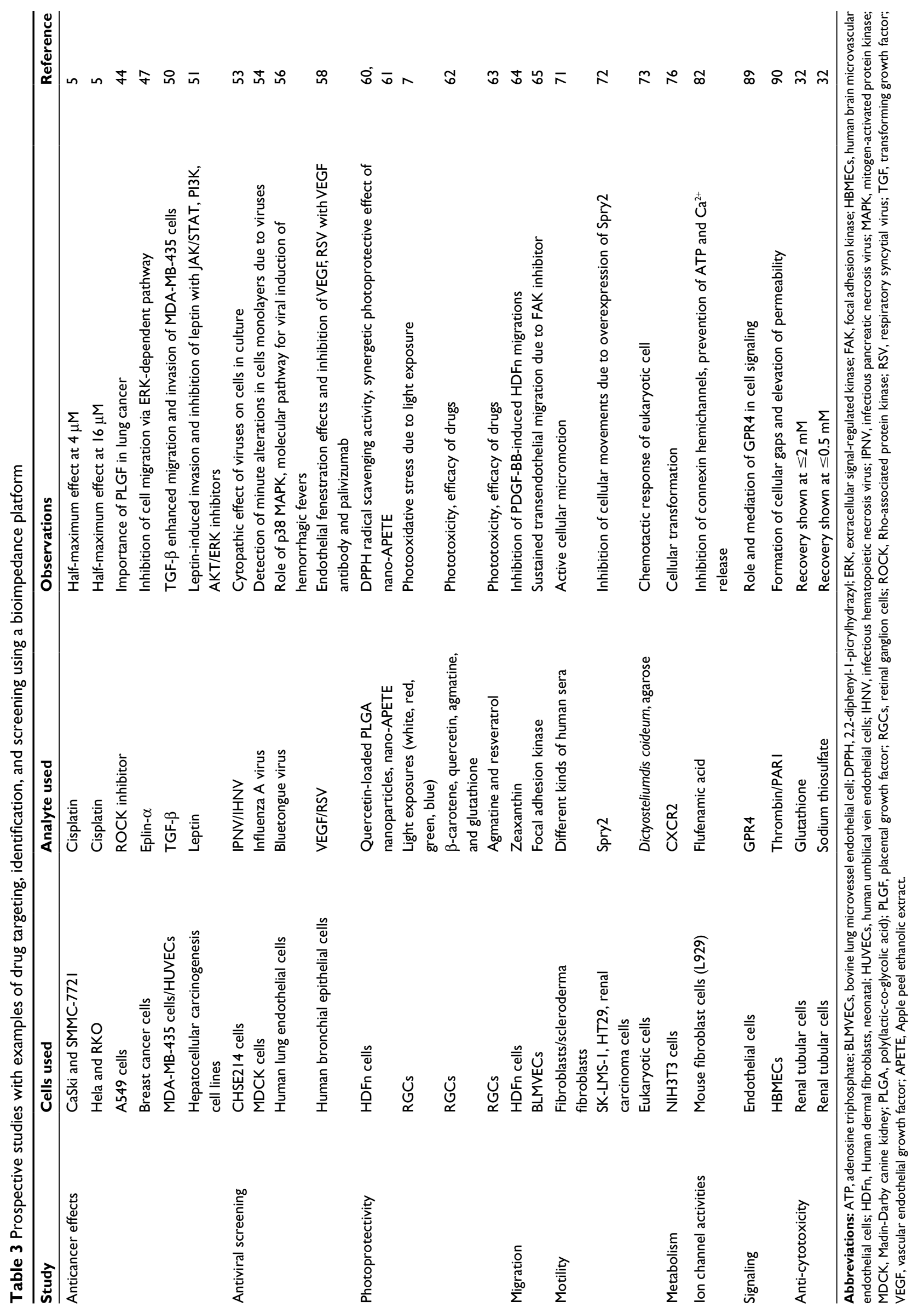


affinity/chemical capture/protein affinity) between the lowmolecular-weight compound and target protein. Most of the drug molecule acts on a specific receptor on the cells, which is have responsible for regulate the body functions and disease, so the receptor specific binding site is the target to develop a new therapeutic agents. For that, many new binding assays have been developed; among these, the ECIS-based receptor binding assay has the potential for HTS of small-molecule targets. These impedance-based biosensor systems have been used to very quickly identify and analyze G-protein-coupled receptor (GPCR) activity. ${ }^{32,33}$ Using impedance assay, several researchers have studied GPCR ligand activity, ligand selectivity, and receptor-ligand analysis, ${ }^{34-36}$ and enzyme actions have been studied through the protein adsorption at the surface of the electrode. ${ }^{37}$ The specific binding efficiency has also been studied on histamine $\mathrm{H} 1$ receptor. ${ }^{38}$ In a study of hematopoietic cell adhesion to bone marrow stroma proteins, the cell growth in suspension did not alter the impedance signal until the cells were attached on the electrode surface, which was coated with binding proteins. In this case, the signal has specifically reflected from the cell binding protein coated surface. ${ }^{39}$

Cellular binding efficiency has been studied with various proteins. The interactions between cells and fragments of fibronectin (FNF) glycoproteins were studied using two histone deacetylase inhibitors, suberoylanilide hydroxamic acid and tubastatin A. Both inhibitors increased cell adhesive properties and kinetics; suberoylanilide hydroxamic acid acted slowly, while tubulin acted rapidly. Enhancement of cellular binding to the FNF was correlated with a reduction of Lyn kinase activity using an anti-phospho-Src antibody. Therefore, Src kinases governing hematopoietic cell adhesion signaling were correlated with c-Src in adherent cells. ${ }^{39}$ In hemostasis, the endothelial cell barrier and its integrity are important for cell survival: if the barrier function is lost, this may lead to autoimmune or infectious disease. The cell junctions and barrier integrity and functions have been studied using the ECIS bioimpedance system. Normally, the vascular endothelial cells express platelet endothelial cell adhesion molecule (PECAM)-1, and PECAM-1 is a cellular adhesion and signaling receptor comprised of six extracellular immunoglobulin, which mediate homophilic adhesion molecule interaction. These interactions are directly responsible for enhancing intercellular junctions, which provide steady-state barrier stability to endothelial cells, and have the capability to recover vascular endothelium. The affinity modulation and homophilic adhesive properties of PECAM-1 were examined in cells by Heng et al and endothelial monolayer resistance was evaluated by ECIS. Endothelial cell monolayer recovery was inhibited by $\mathrm{IgD} 1$-specific $\mathrm{mAb}$ PECAM-1.3 after thrombin-induced disruption, whereas endothelial restoration was strengthened by IgD6-specific $\mathrm{mAb}$ PECAM-1.2. This revealed that the enhanced homophilic binding affinity of PECAM-1 was achieved by IgD6-specific antibodies and its suggested a new kind of therapeutic possibility for treating vascular endothelial injury. ${ }^{40}$

The ECIS system has also been used to study vascular endothelial barrier activity. Platelets play a critical role in maintaining the endothelial barrier properties. Usually, the vascular endothelium acts as a semipermeable barrier for transition of water and protein with the support of platelets. However, it produces a soluble element in the blood conditioned medium, which leads to reduced permeability; the decreased permeability is also associated with a lipid bound to albumin and lysophosphatidic acid present in the blood conditioned medium. Reductions in permeability have been measured by real-time electrical resistance through the vascular endothelial cell monolayers. Endothelial cells were utilized in a study of cAMP/protein kinase A (PKA) enhancement and inhibitor activity. Permeability was independent of both PKA and PKG, which increased the endothelial electrical resistance. However, genistein inhibits the raise of endothelial electric resistance by blocking the tyrosine kinase activity. Furthermore, the blood conditioned medium had increased electrical resistance, resistance through a signal transduction pathway autonomous for $\mathrm{cGMP} / \mathrm{PKG}$ and cAMP/PKA and activation of the signaling pathway was completed with tyrosine phosphorylation and $\mathrm{G}$ protein inhibiton. ${ }^{41}$

Permeability-decreasing activity of platelet conditioned medium was studied in bovine pulmonary artery cell monolayers and microvascular cell monolayers, permeability decreasing activity of platelet conditioned medium resulted as increase in electrical resistance. Increases in electrical resistance were controlled or decreased by Sephacryl S-200, albumin immunoprecipitate, and methanol extract from the albumin immunoprecipitate, which were obtained from the blood conditioned medium. All the immunoprecipitates used in the study were bioactive lipids, which highly regulate permeability. ${ }^{42}$

Transepithelial resistance (TER) is used in ECIS to investigate the paracellular-mediating functions of epithelial cells, especially at tight junctions, and barrier functions. TER measurements cover additional sources of resistance generated by cell-substrate contact. The cell-substrate and paracellular resistance for Madin-Darby canine kidney (MDCK) II cells, laryngeal epithelial cells (HEp-2), and human lung embryonic cells (WI-38 VA13) have been measured. It suggested that the cells cultured on polycarbonate filters, produce extra TER values, which is resulting from cell-substrate contact spaces for each cell type and filter property, because the currents flowed through cell-substrate spaces and tight junctions. ${ }^{43}$ The dynamic 
behavior of cells in culture was examined by measuring electrical resistance over endothelial cells in a monolayer. The TER value indirectly related to the cell permeability of the ion transport mechanism. Therefore, transport studies are important for understanding the paracellular transport function.

\section{ECIS-based anticancer drug screening}

Cancer involves unregulated growth and spread of abnormal cells, which aggressively propagate body organs through systemic circulation, ultimately causing death. Accordingly, identifying suitable bioactive molecules and molecular effects on abnormally behaving cancer cells is of great importance during the early stages of drug discovery. Adhesion properties, cell-cell communication, and cell-substrate binding interaction are essential factors for studying cancer cells and in anticancer drug screening. ECIS-based techniques are very important and powerful tools for investigating the full cellular process in a real-time manner. With ECIS, the important features to observe are the cellular responses such as attachment, spreading, migration, proliferation, differentiation, and invasion as well as the cytotoxicity of compounds or drugs studies with high sensitivity. ${ }^{44}$ Normally, cells grow on a surface with which they have suitable affinity and spread in a single layer, but cancer cells grow very rapidly without any checkpoint restriction of the cell cycle and form into multiple layers with aggregates. At the same time, the cancer cells can not be subject to this normal safeguard. Accordingly, the continual monitoring of above all parameters is crucial for understanding cellular behaviors, ECIS is a suitable method for studying the dynamic cell behaviors and cell cycle and achieving quantification of cellular processes. ${ }^{45}$ In cancer studies, cell invasion, signal transduction, and cell migration are the main focus, as these processes are responsible for the regulation of cellular behavior through intracellular and extracellular signal transduction pathways. Movement of a cell from one place to another is known as cell migration. This study has been described in a separate section. Cell invasion is related to the penetration of cells to an extracellular matrix or a monolayer of cells and is associated with metastasis. In cancer, a variety of growth factors and genes facilitate this process.

At the molecular level, oncogenes and tumor suppressor genes are two important genes in cancer. Understanding these genes will aid in the development of new drugs for cancer therapy. Furthermore, various growth factors and their binding proteins and or receptors are the responsible for the various cancer (benign and malignant tumours) cell proliferation, differentiation and apoptosis, and are key factors for therapeutic active drug development and screening. Particularly in lung cancer, placental growth factor (PLGF) plays a major role in cell spreading, motility enhancement, and regulation and is responsible for stimulation of tumor angiogenesis and inflammation. Chen et al investigated the role of PLGF in human non-small cell lung cancer cell line (A549). This cell line is created into three different expressed sublines such as A549 ${ }^{\triangle \mathrm{PIGF}}$ (anti-P1GF ribozyme transgene), A549 ${ }^{\mathrm{WT}}$ (wildtype), A549 ${ }^{\mathrm{pEF} / \mathrm{His}}$ (empty plasmid) and were used. All the cell type were checked with ROCK-1 (Rho associated kinase) expression which is responsible for regulation of cell adhesion and migration. The results indicated that it was more diminished in A549 ${ }^{\mathrm{PIGF}}$ than in the other cells compared to A549 ${ }^{\mathrm{WT}}$ and A549 ${ }^{\mathrm{pEF} / \mathrm{His}}$ cells, revealing that PLGF precisely coordinated the cancer cell motility and indicating lost response of A549 ${ }^{\triangle \mathrm{PIGF}}$ cells to Rho-associated protein kinase (ROCK) inhibitor. ${ }^{46}$ The prostate transglutaminase (TGase-4) enzyme is overexpressed in prostate cancer and cell adhesion properties reduced, causing the disruption of paracellular pathway by passing through ROCK pathway, thus the ROCK pathway has wide-ranging implications for cancer cells. TGase-4 plays an important role in the interaction between cancer cells and endothelial cells. ${ }^{47}$ Overexpression of TGase-4 may suppress the growth of target cells, likewise Eplin- $\alpha$ reduces the growth of human breast cancer cells. In ECIS observations, expression of Eplin- $\alpha$ in human breast cancer cells was found to slow down wound recovery (reduction of both capacitance and resistance), as observed by several inhibitors. Extracellular signal-regulated kinase (ERK) inhibitor only partially restored the inhibitory effect on motility in cancer cells. Thus, overexpression of Eplin- $\alpha$ reduces growth and inhibits cell migration via an ERK-dependent pathway and it increases survival in patients with breast cancer. ${ }^{48}$

The tumor suppressor gene plays a central role in multiple types of human cancer. Metastasis occurs when cancer cells gain the ability to attack neighboring cells and tissues. It is important to understand the migratory, adhesive, and invasive capabilities of malignant tumors. Importantly, expression of aryl hydrocarbon receptor repressors (AHRR) in human cancer cells decreased anchorage-dependent and anchorage-independent cell growth in vitro and minimized angiogenic potential. Therefore, the downregulation of AHRR is an effective way to minimize the angiogenic potential. The downregulation of AHRR was quantitatively evaluated ${ }^{49}$ and Downregulation of AHRR is found to be better choice for establishing novel therapeutic intervention approaches against various cancers.

CD44 is a multi-structural cell-surface glycoprotein that is involved in essential physiological activities in normal cells, such as adhesion, proliferation, migration, as well as cell-cell interactions and signaling pathway regulation. Significantly, the structural and functional properties of CD44 are also 
related to tumor cell invasion and metastasis. ${ }^{50}$ Real-time impedance measurements were carried out using human breast cancer carcinoma cell lines to assess invasive properties, and it was found that the human breast carcinoma cells (MDAMB-435) invaded into HUVECs. Transforming growth factor (TGF)- $\beta$-pretreated MDA-MB-435 cells were added to the HUVEC monolayer. After 1 hour, endothelial cells were invaded by (TGF)- $\beta$-treated cells, and cell-cell contacts between HUVECs decreased resistance after 4 hours. These results suggest that (TGF)- $\beta$ induces cell division as well as improves migration and invasion of MDA-MB-435 cells. ${ }^{51}$

In the study of malignant hepatoma, the human hepatocellular liver carcinoma cell line has been utilized for analysis of invasive properties. The invasive properties and effects of leptin on cell migration have been quantitatively evaluated, and leptin was found to play a key role in energy balance, body weight control, and growth factor regulation in hepatocellular carcinogenesis. Using ECIS, after HUVECs reached confluence, hepatocellular carcinogenesis cell lines were introduced for analyzing the invasive properties. Reduced impedance revealed that invasion was initiated from endothelial cell junctions, and extravasation of hepatocellular carcinogenesis cell lines occurred on the substratum. Mainly, leptin-treated cells experienced that reduction was greater in leptin-treated cells than in controls, which suggests that invasiveness increased in both HepG2 and Huh7 cells. Additionally, the invasions were successfully inhibited by pharmacological inhibitors of JAK/STAT, PI3K, and AKT/ ERK signaling pathways. ${ }^{52}$

\section{ECIS-based antiviral drug screening}

Viral infections are a major problem for humans worldwide. They cause many life-threatening diseases and are often responsible for morbidity and mortality. Furthermore, incidence rates continue to increase. Minimum number researches with specific action to viral diseases has been reported so far based on the ECIS-HTS method. Viruses have the ability to generate resistance against antiviral treatments, and antiviral drug screening efficacy are limited. When creating novel antiviral agents, the therapeutic host targets should be identified so that the spread of infection can be prevented or reduced. Reproduction of viruses in cells occurs in various phases, including the eclipse phase, the log growth phase, and cell lysis during the release of virus particles. ${ }^{53}$

Campbell et al investigated viral infections in cultured cells using ECIS. Chinook salmonid embryonic stem cells (CHSE214) were tested with infectious pancreatic necrosis virus and epithelioma papulosum cyprini cells were tested with infectious hematopoietic necrosis virus, and the cytopathic effects were observed in the cells, which resulted in dramatic impedance changes. At $50 \%$ tissue culture infective dose, dilution of virus caused CPEs on half of the given cell population, resulting in cell death along with remarkable changes in impedance. CHSE-214 showed increased impedance as well as reduced capacitance after introduction of infectious pancreatic necrosis virus after 30 hours, resulting in decreased resistance. The results confirmed that the viral infection inducing cytopathic effect in an dose-depended manner. ${ }^{54}$

Over the past decade, virus-induced CPE has created challenges in the evaluation of cultured cells. However, the bioimpedance system has emerged as a means to overcome evaluation challenges. ECIS is a dynamic process for screening antiviral compounds effectively in real time, wherein reduction of the impedance signal from cell monolayers represents the effectiveness of viral infection. McCoy and Wang quantified the CPE of influenza A virus-infected MDCK cells in real time by using ECIS. Influenza A virus-infected MDCK cells were cultured. One hour after inoculation, the media containing viruses were replaced with maintenance media (ammonium chloride $\left[\mathrm{NH}_{4} \mathrm{CL}\right]$ ), and the virus entry inhibitor was used to monitor inhibition of the $\mathrm{CPE}$ of virus-infected MDCK cells. Influenza A virus infected the healthy MDCK cell monolayer, which displayed a rounded cell structure and detachment. The results showed an initial increase in resistance from 7-8 hours, followed by a reduction in the impedance level. Moreover, $\mathrm{NH}_{4} \mathrm{CL}$-treated cells showed similar results as influenza-infected cells, and the treatment response revealed recovery of resistance due to antiviral activity. ${ }^{55}$ However, regarding multiplicity of infection (MOI) adjustment, the basic step for most downstream applications can be adjusted by increasing/decreasing the number of cells. But, still an implicated issue about physiological effects is that the application of viral vector often has toxic effects on individual targets. Therefore, Muller et al was developed an ECIS based assay to control the viral dose in order to attain the specific effects, for that they introduced significant dosage of adenoviral transfection vector (Ad5 derivate) into a porcine epithelial cell line (IPI-2I) and were investigated, and this shows dose-depending toxic effect. Toxicity analysis of the MOI level was carried out at various concentration ranges, and the data showed a high linearity in regression coefficient and logarithmic correlation with a rapid toxic response at the lowest MOI levels. The results determined the minimal nontoxic dose as well as the level of cell death due to MOI in each transfection in a real-time manner. ${ }^{56}$

Endothelial cell permeability and barrier functions play a significant role in causing viral fevers, including viral hemorrhagic fever, and dengue fevers, as well as virus 
replication, which are causes of high morbidity and mortality. This disease is associated not only with direct viral damage to cells, but also deregulation of inflammatory functions. Intracellular replication occurs during most stages of the viral life cycle; during the replicative process, the double-stranded RNA (dsRNA) stimulates inflammatory responses. Rotaviruses and bluetongue virus (BTV) have been examined for the endothelial cell barrier deregulation, leakage of the vascular endothelium, and p38 mitogen-activated protein kinase (MAPK) activation in an in vitro model. BTV is the agent that causes hemorrhagic fever in ruminants. BTV-infected human lung endothelial cells showed a dose-dependent reduction of TER, thus illustrating cytoskeletal rearrangement and direct viral intervention. Moreover, dsRNA had a similar effect as BTV on the endothelial barrier, whereas p38 MAPK inhibited endothelial barrier dysfunction caused by both BTV and dsRNA and stimulated inflammatory cytokine production as well as vascular permeability. Collectively, the presence of both dsRNA and activated p38 MAPK together was shown to be a possible molecular trigger of viral induction of hemorrhagic fevers, which suggests that blockage of the p38 MAPK pathway may be one clinical approach to target viral-induced hemorrhages. ${ }^{57}$

The effective release of cytokines during infection is the result of induction of respiratory syncytial virus (RSV), which is a major cause of respiratory diseases, as the bronchial tissue permeation is altered by cytokines such as vascular endothelial growth factor (VEGF). ${ }^{58}$ This permeability change has been studied using ECIS, and the study showed that RSV infection influenced bronchial epithelial monolayer permeability through induction of VEGF. VEGF antibody and palivizumab were used to inhibit the induction of VEGF and RSV infection. The results showed that decreased resistance was associated with enhanced permeability, which was inhibited by VEGF antibody and palivizumab. Reduction of epithelial resistance and elevation of cell-cell gap formation were stimulated by the release of VEGF, which resulted in acceleration of bronchial hyperpermeability. ${ }^{59}$

Overall, ECIS is a valuable tool for screening antiviral compounds and the viral response in cultured cells.

\section{ECIS-based photoprotective drug screening}

Light radiation plays an important role in various acute and chronic skin conditions, such as barrier dysfunction, photoaging, wrinkling, wilting, laxity, sagging, patchy pigmentation, dryness, and skin cancers, as well as in oxidative stress and toxicity effects. Light can be absorbed by biologic chromophores, which leads to mitochondrial oxidative stress and causes cellular dysfunction and even cell death. As such, the oxidative stress pathways are possible therapeutic targets for the development of new therapeutic drugs for photooxidative diseases and for exploration of photooxidative and protective mechanisms. Photoprotection is the primary preventative approach in skin care. Routine use of sunscreens is associated with reductions of actinic keratosis, squamous cell carcinoma, and melanoma risk. In erythropoietic protoporphyria, use of sunscreens fails to block visible light of the blue spectrum, leading to toxic reactions. Photoprotective drugs have enhanced properties against photosensitization as well as photo-induced dermatosis. Such drugs work by activating the pigmented barrier (melanin) between light and skin. Bennet et al utilized the ECIS system for the study of continuous light radiation toxicity and protective effects of various drug formulations. Cellular behaviors of skin cells were investigated in a real-time manner; a custom-made, artificial light setup was established with ECIS to conduct real-time light-induced cell monitoring. ECIS data of cellular activities in response to photooxidative stress correlated well with data from other standard assays. In this study, different kinds of protective agents were used, such as flavonoids, carotenoids, neuroprotective agents, and antioxidants, and the protective agents were entrapped with polymers to prevent irradiation. Quercetin-loaded poly(lactic-co-glycolic acid) nanoparticles and raw drug candidates were examined in light-induced Human dermal fibroblast, neonatal cells (HDFn) cells. The prepared nanoparticles showed enhanced therapeutic efficiency; importantly, photoprotective effects were higher in HDFn cells treated with nanoparticles than in those treated with raw drugs, because the raw drug was irradiated by light. This suggests that early detection of photooxidative stress by HTS as well as improved action on the targeted area are essential concerns for therapeutics. ${ }^{42}$

Similarly, natural bioactive molecules act as adjuvants in the photooxidative mechanism. The bioactive molecules may be unstable in various environmental conditions such as light, temperature and some other unpleasant conditions that make the bio-molecules ineffective in targets. In order to overcome these drawbacks, natural bioactive molecules were nanoencapsulated with suitable polymer and studied for photo-protective effect by using ECIS system. To enhance the photoprotective proficiency and effectiveness of phytodrugs, biocompatible polymer was applied as a nanocarrier of phytodrugs with permeation enhancer (oleic acid); which can enhance the permeation of phytodrugs, then the nanoparticles' effects were studied in HDFn cells. Based on real-time evaluation, the concentration of $50 \mu \mathrm{M}$, showed the highest efficiency, and this concentration had a strong synergistic 
photoprotective effect. Improved activity on the target area is an important concern in developing therapeutic applications for the skin. ${ }^{60,61}$ These studies suggest that the ECIS system can convenient and rapidly measure the photoprotective effects of drugs in an in vitro model as HTS evaluation.

Oxygen consumption in eye cells decreases during light radiation exposure, which leads to the formation of reactive oxygen species (ROS). High production of ROS can cause several neurodegenerative diseases, cell stress, retinal photodamage, and retinal disorders. Light-induced eye cell damage and protective drug effects were recently investigated by Bennet et al who used different-colored artificial light (white, red, green, and blue) in retinal ganglion cells (RGC-5) to quantifying the stress effect by time-dependent response by using ECIS system. The results showed decreased impedance values and decreased transcellular resistance. From the analysis, rapid reduction of the impedance level occurred after exposure to red and blue light, whereas the lowest impedance drop was observed upon green light exposure. The data revealed that light exposure delayed activity and decreased the strength of RGC- 5 cells. These functions may be related to reductions in the levels of stress factors and protein markers. ${ }^{62}$

Cell responses to different drugs ( $\beta$-carotene, quercetin, agmatine, and glutathione) at different concentrations have also been evaluated; the most cell-tolerated and nontoxic activities were found to occur with $0.25,0.25,0.25$, and $1.0 \mathrm{mM}$ of each drug, respectively. Glutathione was found to be a most effective protection against light radiation toxicity among the four samples. This system ECIS based demonstrated direct evaluation of photoprotective effects. ${ }^{62}$

Recently, resveratrol and agmatine were proved to minimize light-induced cell damage by preventing the elevation of free radicals, nitric oxide, calcium gating, and TNF- $\alpha$. Comparing these two compounds, resveratrol helps heal damaged cells, and provided significant information on photooxidative stress interventions. ${ }^{63}$

\section{ECIS-based pharmacological profiles of various drug candidates Cell migration-based drug screening for healing}

In an in vitro model, migration describes directed cell movements, which allow cells to alter their positions within tissues. Using ECIS, various cellular activities have been studied, such as wound healing, cancer, inflammation, and cell growth and differentiation with different cell lines, including keratinocytes, myocytes, fibroblasts, melanocytes, endothelial and epithelial cells, and macrophages, which provide a range of growth factors that are responsible for the migration process and that are targets for new drug development. Using ECIS, different methods of wound healing property analysis have been followed, such as mechanical wounding (scratch assays) and electrical wounding (high direct current pulse). In scratch assays, researchers use a pin or needle to scratch and remove some cells from a cell layer to create an empty region, and the edges of the wound can migrate to heal the wound. Because of uneven scratch, wound healing assays have been modified with a new technique, electrical wounding, to ensure the standardized wound sizes and edges. In one study, an electric current was applied to the cell monolayer to create a wound, which means that cell death occurred; this resulted in decreased impedance, and repopulation, measured by increased impedance, was observed, which means that the cells migrated into the wounded area until the wound completely healed ${ }^{64}$

Many bioactive compounds have been studied to date. Initially, for the establishment of an electrical wound healing assay, Keese et al developed an assay based on ECIS to determine the recovery and migration effect on wounded cells by measuring the impedance in BS-C-1 (African green monkey kidney cells; CCL-26), normal rat kidney (CRL-6509), and MDCK (CLL-34) cells. In this study, the cells grown on electrode were monitored with ECIS and subjected to DC pulse currents, leading to severe electroporation followed by cell demise. After this, the cells were treated with various percentages of serum, and the electrode impedance was recovered, which indicated migration and ultimate healing of the wound cells. ${ }^{65}$

Recently, Wu et al investigated the effects of zeaxanthin on migration of human foreskin fibroblast cells (Hs68) in response to platelet-derived growth factor (PDGF)-BB and human metastatic melanoma cells (A2058) using a non-contact co-culture method. Hs68 cells were seeded in ECIS wells containing serum-free medium, and $\mathrm{AC}$ was applied to the electrodes to form a wounded area. After the initial reading, the medium was replaced with zeaxanthin medium, and the injured areas were healed by cell migration. Responses were measured by recovery of electrical impedance. The results showed that zeaxanthin is an efficient inhibitor of $\mathrm{Hs} 68$ cell migration induced by PDGF-BB and A2058 cells. ${ }^{66}$

In an inflammatory response study, transendothelial electrical resistance assay has been used for evaluation of adherent neutrophils (PMNs) transmigration property, and the PMNs transmigration through the endothelium cell monolayer of cell junctions sites. In this model study, the PMNs penetration to HUVEC monolayers was evaluated, and tight junctions between adjacent endothelial cell layer disruption were observed. ECIS was used to evaluate tight junctions in HUVEC 
monolayers that were cultured in astrocyte media. ECIS and immunofluorescence revealed that the activated with IL-8 PMN adhesion to resting monolayers then migration across interleukin-1-treated monolayers demonstrated non-pervasive proteolytic loss of tight junction proteins (ZO-1, ZO-2, and occludin). The results showed that electrical resistance remained unchanged, while the endothelial barrier was preserved by PMN migration at tricellular corners, and that there was no extensive disruption of endothelial tight junctions. ${ }^{67}$

Concerning the migratory properties of cancer cells, transendothelial migration plays a vital role in the formation of metastatic cascades, which go on to cause secondary tumors. Transendothelial migration of cancer cells is promoted by the focal adhesion kinase (FAK) due to 2-dimensional migration of cells on extracellular matrix proteins. Sarah et al investigated the transendothelial migratory properties of AU-565 breast adenocarcinoma cells to bovine lung microvessel endothelial cell monolayers using ECIS. The results showed that monolayer resistance was significantly decreased by AU-565 cells treated with FAK siRNA, and this expressed FAK-related non-kinase (FRNK) inhibitor in AU-565 cells and leads to breached monolayers integrity, which showed a decrement in transendothelial migration within 15 hours. Exposure to an FAK-related non-kinase inhibitor resulted in sustained transendothelial migration, whereas nonmetastatic cells had no impact. Based on the overall results, FAK affects the metastatic cascade. ${ }^{68}$ Also, various factors involves in cell migration. In one study shows that the platelet-derived growth factors (PDGF) $\beta$ receptor is triggered the cell migration, this cell migration is inhibited by the sphingosine 1-phosphate receptor-1 $\left(\mathrm{S}_{1} \mathrm{P}_{1}\right)$. Analysis showed that SB649146 inverse agonist minimized endocytosis of the PDGF- $\beta$ receptor-S1P ${ }_{1}$ receptor complex, thereby reducing stimulation of $\mathrm{p} 42 / \mathrm{p} 44 \mathrm{MAPK}$ and migration due to PDGF. These results with SB649146 suggest that dynamic endogenous $\mathrm{S}_{1} \mathrm{P}_{1}$ receptor strengthens PDGF-induced cell migration. ${ }^{69}$ Cell migration response, including antitumor activity, anti-inflammatory activity, and signaling, has been the subject of numerous studies, but this study also supports the therapeutic potential of various drugs in the treatment of wound healing.

Overall, this bioimpedance method provides real-time information, and the resulting data are similar to those obtained in traditional assays.

\section{Drug screening based on enzymatic activity}

Enzymes play a vital role in every type of cellular activity, including active/passive transport, signaling pathways, respiration, metabolism, gene expression, and enzyme kinetics. As such, cellular processes are useful targets in new drug/therapeutic active agent development. ECIS offers a broad range of applications for detecting various cellular processes, including enzymatic and protein activity. Some cellular activities have been explained in previous sections. This section will cover enzymatic inhibition and activation in various interventions, including how the activity is controlled and how the drug/therapeutic agent inhibits or activates the enzyme. Various disease diagnosis and treatments have been studied with regard to enzymatic activity measurement using ECIS. Some important examples of enzymatic activities are detoxification and cytokinesis, both of which are important for normal cellular processes. These normal cellular processes involve enzyme kinetics, which have been monitored by ECIS with the help of micromotion activity measurement. Large fluctuations in motility, which is a fundamental biological process in cultured cells, were observed during the growth phase. Nanometer changes in cell diameter as well as subnanometer changes in the distance between the ventral cell surface and substrate significantly change the impedance. This subtle aspect of cell motion is known as micromotion (micromotions of living cells describes the fluctuations in impedance). Confluent layers and cell temperature are intimately linked with metabolic activity and impedance fluctuation in ECIS. ${ }^{70}$ Measurement of impedance continues to fluctuate as a manifestation of cellular metabolism and constant motion after full spreading of cells. ${ }^{71}$ Cellular motion can be defined as the active vertical movement of a group of cells. The micromotion of normal fibroblasts and scleroderma fibroblasts from various human sera has been investigated, and the micromotion of scleroderma fibroblasts was more dynamic than that of normal fibroblasts, suggesting that in vivo activities may motivate scleroderma fibroblasts to exhibit active cellular micromotion. ${ }^{72}$ One factor to consider in the in vitro model is that overexpression of enzymes in cells, which reduces the cell function and activity due to enhanced cell attachment and spreading and increased focal adhesion, and also limits cell movement. Lee et al investigated the overexpression characteristics of Spry2, a negative regulator of receptor tyrosine kinases, using different cell types in an in vitro model. SK-Spry2 cell movement was blocked due to improved adhesion and increased formation of stress fibers. Overexpression resulted in reduced cellular functions and cytokinesis activity. ${ }^{73}$ With regard to detoxifying enzyme activity, chlorogenic acid was found to inhibit the proliferation of A549 human cancer cells, and also inhibited 12-O-tetradecanoylphorbol-13-acetate induced neoplastic transformation of JB6 cells in a dose-dependent manner. 
A low dose inhibited phosphorylation, which is responsible for various kinase regulation and higher dose inhibits ERK. The results showed that the chlorogenic acid upregulated the cellular antioxidant enzymes and also suppresses the ROS mediations. ${ }^{74}$

The permeation of metastasis into secondary sites is an intrinsic characteristic of cells and is initiated by folate, which is responsible for site specific binding to dihydrofolate reductase. These stimuli can be differentiated into two types: chemotactic, which is directional cell movement in response to external stimuli, and chemokinetic, which is cellular movement that is not in a specific direction. In a study on the contribution of the chemotactic response to cancer cells, dictyostelium discoideum was depleted in motile eukaryotic cells and observed with an ECIS/taxis system. The inoculation of cell at the target electrode was equivalent to the dose of folate required for cell stimulation. The lack of chemotactic response and interference of an agent with chemotactic motility resulted in delayed cell movement on the target electrode, which is useful in the evaluation of agonist and antagonist movements. ${ }^{75}$ This ECIS system allows for the study of various diseases, including the evaluation of active drugs and other compounds in a noninvasive manner.

\section{Cellular metabolic activities}

With use of bioimpedance systems, metabolism studies are creating a more physiologically relevant model of various types of cellular metabolism, and such systems can help to identify drugs with high potential in preclinical novel drug development. In early stage drug development program were mainly deals with pharmacokinetic and pharmacodynamic studies along with toxicity studies, which is highly recommended to screening the new drugs. Most biological activities depend on energy metabolites, actions, and transformation. General characteristics of cell metabolic activities are the uptake of metabolites, pathways regulating metabolisms in cells, energy metabolism, and elimination of waste acid and byproducts. This ECIS based measurement system provides a reliable way to measure the transformation of cellular parameters. Generally, during cell proliferation in the primary stages of cell-based study, serum is essential for adhesive contact of cells. After cell adhesion, cell crawling requires the formation of focal adhesions and arrangements of the actin cytoskeleton. ${ }^{76}$ In one study, the transformation measurement was carried out with an active chemokine receptor, which is a GPCR that normally participates in cellular activation and migration, although a single amino acid substitution leads to constitutive activity. NIH3T3 cells were transformed with constitutively active chemokine receptors, and cell growth and foci development were measured. ${ }^{77}$ The study demonstrated that this could be promising way of screening various anticancer drugs that involve cellular transformation. Furthermore, the ECIS system showed that electrical stimulation leads to enhanced insulin response in human muscle skeletal cells. The fusion of myoblast cells was differentiated into multinucleated myotubes, and the micromotion measurements were based on changes in the impedance. Based on the micromotion measurement, caffeine-stimulated cells showed enhanced micromotion and enhanced contraction, which revealed that the caffeine increased uptake of deoxyglucose $29 \%$ following electrical stimulation. Of note, electrical stimulation enhanced insulin activity in hyperglycemic cells and also enhanced regulation of blood glucose homeostasis. $^{78}$

In another study, cellular metabolism, growth status, and extracellular acidification rate (ECAR) were measured using an ECIS integrated light-addressable potentiometric biosensor. Renal cells were used for the study. Triton X-100 was introduced into the ECIS cell chamber after 2.5 hours, and impedance drastically decreased to low levels. Cell index values were calculated. These values were high when there was increased in cell attachment, and dropped after the addition of drugs. Meanwhile, $\mathrm{pH}$ measurement was conducted with a light-addressable potentiometric biosensor, and pump-off and pump-on protocol was followed to measure the ECAR. After the addition of Triton X-100, ECAR levels gradually decreased, and the ECAR values were calculated. In response to Triton X, cell metabolism was reduced to a low level. Employment of combinational biosensors has thus been demonstrated for studying cell status and cell metabolism. ${ }^{79}$

\section{Ion channel activities}

Based on cellular functions, the properties of action potential, ion channel signals, and cellular responses can be monitored. These properties provide a direction for detection of chemical and biological analytes as well as screening of various toxins and drugs, and drug screening. Ion channels regulate the movement of ions across cell membranes and play an essential role in human physiology, as they help regulate cellular ion homeostasis, fabricate electrical activity in nerve and muscle cells, and regulate the release of transmitter and hormones. The regulation of ion channel activity has been proven to be an important approach in various interventions. Ion channel targets are considered an important factor in drug screening approaches. ${ }^{80}$ Screening new drugs for ion channel modulators (inhibitors and activators) requires high sensitivity with HTS. In one study, the electrophysiological 
properties of cells were determined based on the capacitance values and resistance of the cell membrane. The impedance was calculated with differentiating the cells and the equation using voltage and current phasors, which were obtained by COSMOL Multiphysics ${ }^{\mathrm{TM}}$ advanced modeling, ${ }^{81}$ which can provide real-time electrophysiological data about the cells. The cell membrane showed higher capacitance values when ion channels were blocked. Apoptosis caused by loss of dielectric properties in the cell membrane results in an impedance drop. For connexin hemichannel activity measurement, ECIS was used to monitor the synchronous oscillation in a real-time manner; which is responsible for the extension/contraction of lamellipodia and is inducted by the signals from the actomyosin complex. This oscillation was controlled by connexin hemichannel inhibitors, and hindered ATP and calcium release. ${ }^{82}$ For cellular barrier study, the endothelial barrier functions are essential for keeping tissue blood separate from the circulation. Bioelectric dosimetry studies often provide valuable information on the vasculature and superficial vessel permeability. ${ }^{83}$ At low exposure to $\gamma$-radiation, human coronary arterial cells are perturbed in the heart and show changes in cytoskeletal rearrangement, permeability, and endothelial barrier function. ${ }^{84} \mathrm{At}$ the molecular level, death of endothelial cells in response to radiation is associated with activation of stress-activated kinase cascades, which involves transduction of radiation damage via $\mathrm{p} 38$ and JNK. ${ }^{85}$ When ion channels were inhibited, the measured impedance decreased. These studies show that this ECIS system can contribute valuable information about ion channel activities in cellular-based studies. ${ }^{86}$

\section{Cell signaling}

Cell signaling regulates basic intra- and extracellular activities, coordinates cellular actions, and responds to various environments. Typically, cells receive chemical signals via different signaling molecules, whereas signaling molecules are bound by suitable receptors on the cell surface. This prompts a chain of events that transmits a signal inside the cells. Errors in cellular signaling pathways, information, and communication can lead to diseases such as cancers and autoimmune diseases, and understanding of cell signaling might be helpful in determining efficient treatments for various diseases. For example, the vascular endothelium monolayer has its own semipermeable barrier to regulate the transvascular movement of various biomolecules. The cytoskeleton tightness and paracellular gaps can determine the permeability of biomolecules. Also, the expression of Verge (vascular early response gene) protein determines the permeability due to regulation of protein kinase C (PKC). Verge protein expression has been enhanced by cysteine proteinase inhibitors. Phorbol esters activation leads to actin cytoskeleton restoration and reformation of paracellular gaps between cell peripheries. This transvascular movement has been studied on phorbol 12-myristate 13-acetate, an effective tumor promoter that activates the signaling enzyme PKC. The study reported that Verge functions as an active regulator of endothelial cell signaling. ${ }^{87}$

Signaling events also involve mediators such as TGF- $\beta$, which enhances pulmonary endothelial permeability. This has been investigated through RhoA or Rho kinase activation in response to TGF- $\beta$. TGF- $\beta$ is an active inflammatory mediator that increases pulmonary endothelial MLC phosphorylation, and it is associated with formation of stress fibers, cell gap formation, and protein permeability during acute lung injury. Posttreatment, TGF- $\beta$ sustained activation of RhoA with improved MLC phosphorylation. The exoenzyme C3 and Y-27632 inhibitor blocked MLC phosphorylation, and moderately inhibited the TGF- $\beta$-induced modification of action and restores barrier integrity. Cells were infected with active RhoA adenovirus by TGF- $\beta$-induced signaling, resulting in elevated MLC phosphorylation and actin content. The data indicated that the RhoA or Rho kinase pathways are important for mediation and that independent signaling mechanisms are contribute with TGF- $\beta$-induced cytoskeletal organization. ${ }^{88}$

Lysophosphatidylcholine (LPC) is a proinflammatory lipid, and its signal increases endothelial permeability. Human dermal microvascular cells and bovine pulmonary microvascular cells were treated with LPC, and the transendothelial resistance was monitored. The LPC activated membrane-associated $\mathrm{PKC}$ phosphotransferase activity was in absence of translocation of PKC alpha or beta, and both signaling pathways were at baseline levels within 1 hour. Furthermore, three types of pretreatment approach such as GO-6983, PMA induced depletion of PKC alpha, and transfection of antisense PKC alpha oligonucleotide were employed to prevent the LPC-induced resistance. The evaluation showed that each inhibitor blocked $40 \%-50 \%$ of LPCinduced resistance by inhibiting RhoA with $\mathrm{C} 3$ transferase. The results suggested that LPC reduced endothelial barrier function, and that elevated LPC can regulate the activation of proinflammatory endothelial barriers. ${ }^{89}$

There are several studies that show that LPC is proinflammatory and atherogenic, increases permeability, and activates cytokines and adhesion molecules, this has been inhibited by various signaling pathways and mediators. The overall results suggest that GPR4 in endothelial cells may 
play a significant role in the inflammatory response mediated through LPC. ${ }^{90}$

Endothelial cells are considered to be one of the main target of thrombin action and are involved in many actions, such as production of cytokines and chemokines and expression of adhesion molecules. On endothelial cells, thrombin mediates activation of protease-activated receptors (PARs) 1-4. To evaluate endothelial barrier dysfunction, $\mathrm{Ca}^{2+}$ signaling was carried out by thrombin and PAR1-AP in human brain MVECs. Activation of thrombin depends on the lysis of the endothelial barrier, gap formation, and elevated permeability, and dysfunctions occur in response to thrombin stimulation. Exposure of thrombin resulted in 52\% TER, whereas PAR1-AP showed no serious reduction in TER. The results showed that stimulations by thrombin and PAR1-AP vary in TER measurement. Of note, PAR1-AP-induced $\mathrm{Ca}^{2+}$ incursion was not adequate to affect endothelial barrier functions. ${ }^{91}$

Signaling pathways-based screening is highly efficient and can provide useful information on known pathways. Signaling-based drug discovery and screening techniques are still under investigation for many unknown analytes.

\section{Conclusion and future perspectives}

Impedance-based cellular biosensors have remarkable potential for use as reliable and sensitive sensors for pathogen detection as well as for HTS evaluation of toxins and bioactive compounds for clinical and pharmaceutical applications. Impedance-based biosensor systems are strong candidates for use in drug screening tests due to their realtime, label-free, noninvasive, and continuous measurement properties. ECIS is an conventional systematic method with high sensitivity, and it allows rapid approaches to prediction, diagnosis, and treatment of various diseases. ECIS can fully recognize cellular behavior in response to various new bioactive compounds or drugs. Based on the results of the studies described herein, ECIS is the most suitable method for monitoring cellular behavior in real time to screen new drugs. On the other hand, the bioimpedance system provides information's based one mode of action; this might mean that other mechanisms of action which could offer potentially valuable information about a particular action, are overlooked. As such, multiplexing of an integrated system with readout should be considered. The ECIS system with MEMS technology and integration with image detection techniques could be a possible approach for further advancement in multiplexing readout. In the future, we look forward to the integration of ECIS with standard bioassays, which will enhance the quality of measured data. Such integration could provide complete and relevant preliminary in vivo information about targets and mechanisms of action of novel bioactive drugs, as well as enhance the rate of drug discovery for various interventions.

\section{Acknowledgments}

This work was supported by the research and development program of the Society of the National Research Foundation funded by the Ministry of Science, ICT and Future Planning (2013M3C8A3078806 and 2013M3C1A8A01072922).

\section{Disclosure}

The authors report no conflicts of interest in this work.

\section{References}

1. Giaever I, Keese CR. A morphological biosensor for mammalian cells Nature. 1993;366 (6455):591-592.

2. Asphahani F, Zhang M. Cellular impedance biosensors for drug screening and toxin detection. Analyst. 2007;132(9):835-841.

3. Ehret R, Baumann W, Brischwein M, Schwinde A, Stegbauer K, Wolf B. Monitoring of cellular behaviour by impedance measurements on interdigitated electrode structures. Biosens Bioelectron. 1997;12(1):29-41.

4. Grimnes S, Martinsen OG. Bioimpedance and Bioelectricity Basics. 1st ed. St Louis, MO; 2000.

5. Xu Y, Lv Y, Wang L, Xing W, Cheng J. A microfluidic device with passive air-bubble valves for real-time measurement of dose-dependent drug cytotoxicity through impedance sensing. Biosens Bioelectron. 2012;32(1):300-304.

6. Tran TB, Cho S, Min J. Hydrogel-based diffusion chip with electric cellsubstrate impedance sensing (ECIS) integration for cell viability assay and drug toxicity screening. Biosens Bioelectron. 2013;50:453-459.

7. Bennet D, Kim MG, Kim S. Light-induced anatomical alterations in retinal cells. Anal Biochem. 2013;436(2):84-92.

8. Luong JHT. An emerging impedance sensor based on cell-protein interactions: applications in cell biology and analytical biochemistry. Anal Lett. 2003;36(15):3147-3164.

9. Picollet-D'hahan N. Live cell analysis: when electric detection interfaces microfluidics. Journal of Biochips and Tissue Chips. 2011;S1:001.

10. Xiaoqiu H, Nguyen D, Greve DW, Domach MM. Simulation of microelectrode impedance changes due to cell growth. IEEE Sens $J$. 2004;4(5):576-583.

11. Giaever I, Keese CR. Micromotion of mammalian cells measured electrically. Proc Natl Acad Sci U S A. 1991;88(17):7896-7900.

12. Wegener J, Keese CR, Giaever I. Electric cell-substrate impedance sensing (ECIS) as a noninvasive means to monitor the kinetics of cell spreading to artificial surfaces. Exp Cell Res. 2000;259(1):158-166.

13. Wang L, Wang H, Wang L, Mitchelson K, Yu Z, Cheng J. Analysis of the sensitivity and frequency characteristics of coplanar electrical cellsubstrate impedance sensors. Biosens Bioelectron. 2008;24(1):14-21.

14. Wang L, Zhu J, Deng C, Xing WL, Cheng J. An automatic and quantitative on-chip cell migration assay using self-assembled monolayers combined with real-time cellular impedance sensing. Lab Chip. 2008; 8(6):872-878.

15. Abhyankar VV, Lokuta MA, Huttenlocher A, Beebe DJ. Characterization of a membrane-based gradient generator for use in cell-signaling studies. Lab Chip. 2006;6(3):389-393.

16. Irimia D, Charras G, Agrawal N, Mitchison T, Toner M. Polar stimulation and constrained cell migration in microfluidic channels. Lab Chip. 2007;7(12):1783-1790. 
17. Grover WH, Skelley AM, Liu CN, Lagally ET, Mathies RA. Monolithic membrane valves and diaphragm pumps for practical large-scale integration into glass microfluidic devices. Sens Actuators B Chem. 2003; 89(3):315-323.

18. van der Wijngaart W, Chugh D, Man E, Melin J, Stemme G. A lowtemperature thermopneumatic actuation principle for gas bubble microvalves. J Microelectromech Syst. 2007;16(3):765-774.

19. Toh YC, Lim TC, Tai D, Xiao G, van Noort D, Yu H. A microfluidic 3D hepatocyte chip for drug toxicity testing. Lab Chip. 2009;9(14): 2026-2035.

20. Asphahani F, Wang K, Thein M, et al. Single-cell bioelectrical impedance platform for monitoring cellular response to drug treatment. Phys Biol. 2011;8(1):015006.

21. Ozsvári B, Puskás LG, Nagy LI, et al. A cell-microelectronic sensing technique for the screening of cytoprotective compounds. Int $J \mathrm{Mol}$ Med. 2010;25(4):525-530.

22. Pflüger M, Kapuscik A, Lucas R, et al. A combined impedance and AlphaLISA-based approach to identify anti-inflammatory and barrier-protective compounds in human endothelium. J Biomol Screen. 2013;18(1):67-74.

23. Powers ME, Kim HK, Wang Y, Bubeck Wardenburg J. ADAM10 mediates vascular injury induced by Staphylococcus aureus $\alpha$-hemolysin. J Infect Dis. 2012;206(3):352-356

24. Xiao CD, Lachance B, Sunahara G, Luong JHT. Assessment of cytotoxicity using electric cell-substrate impedance sensing: concentration and time response function approach. Anal Chem. 2002; 74(22):5748-5753.

25. Male KB, Lachance B, Hrapovic S, Sunahara G, Luong JHT. Assessment of cytotoxicity of quantum dots and gold nanoparticles using cell-based. impedance spectroscopy. Anal Chem. 2008;80(14):5487-5493.

26. Bennet D, Kim S. A transdermal delivery system to enhance quercetin nanoparticle permeability. J Biomater Sci Polym Ed. 2013;24(2): 185-209.

27. Opp D, Wafula B, Lim j, Huang E, Lo JC, Lo CM. Use of electric cell-substrate impedance sensing to assess in vitro cytotoxicity. Biosens Bioelectron. 2009;24(8):2625-2629.

28. Curtis TM, Tabb J, Romeo L, Schwager SJ, Widder MW, van der Schalie WH. Improved cell sensitivity and longevity in a rapid impedancebased toxicity sensor. J Appl Toxicol. 2009;29(5):374-380.

29. Curtis TM, Widder MW, Brennan LM, et al. A portable cell-based impedance sensor for toxicity testing of drinking water. Lab Chip. 2009;9(15):2176-2183.

30. Liu F, Nordin AN, Li F, Voiculescu I. A lab-on-chip cell-based biosensor for label-free sensing of water toxicants. Lab Chip. 2014;14(7): 1270-1280.

31. Shih SC, Barbulovic-Nad I, Yang X, Fobel R, Wheeler AR. Digital microfluidics with impedance sensing for integrated cell culture and analysis. Biosens Bioelectron. 2013;42:314-320.

32. Xie F, Xu Y, Wang L, Mitchelson K, Xing W, Cheng J. Use of cellular electrical impedance sensing to assess in vitro cytotoxicity of anticancer drugs in a human kidney cell nephrotoxicity model. Analyst. 2012;137(6):1343-1350.

33. Tarantola M, Schneider D, Sunnick E, et al. Cytotoxicity of metal and semiconductor nanoparticles indicated by cellular micromotility. ACS Nano. 2009;3(1):213-222.

34. McGuinness RP, Proctor JM, Gallant DL, et al. Enhanced selectivity screening of GPCR ligands using a label-free cell based assay technology. Comb Chem High Throughput Screen. 2009;12(8): 812-823.

35. McLaughlin JN, Shen L, Holinstat M, Brooks JD, Dibenedetto E, Hamm HE. Functional selectivity of $\mathrm{G}$ protein signaling by agonist peptides and thrombin for the protease-activated receptor-1. J Biol Chem. 2005;280(26):25048-25059.

36. Reddy L, Wang HS, Keese CR, Giaever I, Smith TJ. Assessment of rapid morphological changes associated with elevated cAMP levels in human orbital fibroblasts. Exp Cell Res. 1998;245(2): $360-367$.
37. Zou ZW, Kai JH, Rust MJ, Han J, Ahn CH. Functionalized nano interdigitated electrodes arrays on polymer with integrated microfluidics for direct bio-affinity sensing using impedimetric measurement. Sens Actuators A Phys. 2007;136(2):518-526.

38. Yu N, Atienza JM, Bernard J, et al. Real-time monitoring of morphological changes in living cells by electronic cell sensor arrays: an approach to study G protein-coupled receptors. Anal Chem. 2005;78(1): $35-43$.

39. Obr A, Röselová P, Grebeňová D, Kuželová K. Real-time monitoring of hematopoietic cell interaction with fibronectin fragment: the effect of histone deacetylase inhibitors. Cell Adh Migr. 2013;7(3):275-282.

40. Mei H, Paddock C, Campbell J, Albrecht R, Newman PJ. Enhancement of endothelial cell barrier function by antibody-driven affinity modulation of PECAM-1. Blood. 2013;122(21).

41. Gainor JP, Morton CA, Roberts JT, Vincent PA, Minnear FL. Plateletconditioned medium increases endothelial electrical resistance independently of cAMP/PKA and cGMP/PKG. Am J Physiol Heart Circ Physiol. 2001;281(5):H1992-H2001.

42. Minnear FL, Patil S, Bell D, Gainor JP, Morton CA. Platelet lipid(s) bound to albumin increases endothelial electrical resistance: mimicked by LPA. Am J Physiol Lung Cell Mol Physiol. 2001;281(6):L1337-L1344.

43. Lo CM, Keese CR, Giaever I. Cell-substrate contact: another factor may influence transepithelial electrical resistance of cell layers cultured on permeable filters. Exp Cell Res. 1999;250(2):576-580.

44. Hong J, Kandasamy K, Marimuthu M, Choi CS, Kim S. Electrical cell-substrate impedance sensing as a non-invasive tool for cancer cell study. Analyst. 2011;136(2):237-245.

45. Wang L, Wang L, Yin H, et al. Real-time, label-free monitoring of the cell cycle with a cellular impedance sensing chip. Biosens Bioelectron. 2010;25(5):990-995.

46. Chen J, Ye L, Zhang L, Jiang WG. Placenta growth factor, PLGF, influences the motility of lung cancer cells, the role of Rho associated kinase, Rock1. J Cell Biochem. 2008;105(1):313-320.

47. Jiang WG, Ablin RJ, Kynaston HG, Mason MD. The prostate transglutaminase (TGase-4, TGaseP) regulates the interaction of prostate cancer and vascular endothelial cells, a potential role for the ROCK pathway. Microvasc Res. 2009;77(2):150-157.

48. Jiang WG, Martin TA, Lewis-Russell JM, Douglas-Jones A, Ye L, Mansel RE. Eplin-alpha expression in human breast cancer, the impact on cellular migration and clinical outcome. Mol Cancer. 2008;7:71.

49. Zudaire E, Cuesta N, Murty V, et al. The aryl hydrocarbon receptor repressor is a putative tumor suppressor gene in multiple human cancers. J Clin Invest. 2008;118(2):640-650.

50. Naor D, Nedvetzki S, Golan I, Melnik L, Faitelson Y. CD44 in cancer. Crit Rev Clin Lab Sci. 2002;39(6):527-579.

51. Kuo YC, Su CH, Liu CY, Chen TH, Chen CP, Wang HS. Transforming growth factor-beta induces CD44 cleavage that promotes migration of MDA-MB-435s cells through the up-regulation of membrane type 1matrix metalloproteinase. Int J Cancer. 2009;124(11):2568-2576.

52. Saxena NK, Sharma D, Ding X, et al. Concomitant activation of the JAK/STAT, PI3K/AKT, and ERK signaling is involved in leptinmediated promotion of invasion and migration of hepatocellular carcinoma cells. Cancer Res. 2007;67(6):2497-2507.

53. Kuznar J, Soler M, Farias G, Espinoza JC. Attachment and entry of infectious pancreatic necrosis virus (IPNV) into CHSE-214 cells. Arch Virol. 1995;140(10):1833-1840.

54. Campbell CE, Laane MM, Haugarvoll E, Giaever I. Monitoring viralinduced cell death using electric cell-substrate impedance sensing. Biosens Bioelectron. 2007;23(4):536-542.

55. McCoy MH, Wang E. Use of electric cell-substrate impedance sensing as a tool for quantifying cytopathic effect in influenza A virus infected MDCK cells in real-time. $J$ Virol Methods. 2005;130(1-2):157-161.

56. Müller J, Thirion C, Pfaffl MW. Electric cell-substrate impedance sensing (ECIS) based real-time measurement of titer dependent cytotoxicity induced by adenoviral vectors in an IPI-2I cell culture model. Biosens Bioelectron. 2011;26(5):2000-2005. 
57. Chiang ET, Persaud-Sawin DA, Kulkarni S, Garcia JG, Imani F. Bluetongue virus and double-stranded RNA increase human vascular permeability: role of p38 MAPK. J Clin Immunol. 2006;26(4):406-416.

58. Roberts WG, Palade GE. Neovasculature induced by vascular endothelial growth factor is fenestrated. Cancer Res. 1997;57(4):765-772.

59. Kilani MM, Mohammed KA, Nasreen N, et al. Respiratory syncytial virus causes increased bronchial epithelial permeability. Chest. 2004;126(1):186-191.

60. Bennet D, Sanghyo K. In ECIS to assess human skin cell photo-oxidative damage. Proceedings of the International Conference on Advanced Nanomaterials and Emerging Engineering Technologies; Chennai; July 24-26, 2013. IEEE; 2013.

61. Bennet D, Kang SC, Gang J, Kim S. Photoprotective effects of apple peel nanoparticles. Int J Nanomedicine. 2014;9:93-108.

62. Bennet D, Kim S. Impedance-based cell culture platform to assess light-induced stress changes with antagonist drugs using retinal cells. Anal Chem. 2013;85(10):4902-4911.

63. Bennet D, Kim S. Effects of agmatine and resveratrol on RGC-5 cell behavior under light stimulation. Environ Toxicol Pharmacol. 2014;38(1):84-97.

64. Kramer N, Walzl A, Unger C, et al. In vitro cell migration and invasion assays. Mutat Res. 2013;752(1):10-24.

65. Keese CR, Wegener J, Walker SR, Giaever I. Electrical wound-healing assay for cells in vitro. Proc Natl Acad Sci U S A. 2004;101(6): 1554-1559.

66. Wu NL, Chiang YC, Huang CC, Fang JY, Chen DF, Hung CF. Zeaxanthin inhibits PDGF-BB-induced migration in human dermal fibroblasts. Exp Dermatol. 2010;19(8):e173-e181.

67. Burns AR, Bowden RA, MacDonell SD, et al. Analysis of tight junctions during neutrophil transendothelial migration. J Cell Sci. 2000; 113(Pt 1):45-57.

68. Earley S, Plopper GE. Disruption of focal adhesion kinase slows transendothelial migration of AU-565 breast cancer cells. Biochem Biophys Res Commun. 2006;350(2):405-412.

69. Waters CM, Long J, Gorshkova I, et al. Cell migration activated by platelet-derived growth factor receptor is blocked by an inverse agonist of the sphingosine 1-phosphate receptor-1. FASEB J. 2005;19(13):509-511.

70. Lo CM, Keese CR, Giaever I. Monitoring motion of confluent cells in tissue culture. Exp Cell Res. 1993;204(1):102-109.

71. Luong JH, Habibi-Rezaei M, Meghrous J, Xiao C, Male KB, Kamen A. Monitoring motility, spreading, and mortality of adherent insect cells using an impedance sensor. Anal Chem. 2001;73(8):1844-1848.

72. Huang CN, Lo CM, Hsu TC, Tsay GJ. Sera from patients with scleroderma inhibit fibroblast micromotions monitored electrically. J Rheumatol. 1999;26(6):1312-1317.

73. Lee CC, Putnam AJ, Miranti CK, et al. Overexpression of sprouty 2 inhibits $\mathrm{HGF} / \mathrm{SF}-$ mediated cell growth, invasion, migration, and cytokinesis. Oncogene. 2004;23(30):5193-5202.

74. Feng R, Lu Y, Bowman LL, Qian Y, Castranova V, Ding M. Inhibition of activator protein-1, NF-kappaB, and MAPKs and induction of phase 2 detoxifying enzyme activity by chlorogenic acid. J Biol Chem. 2005;280(30):27888-27895.

75. Hadjout N, Laevsky G, Knecht DA, Lynes MA. Automated realtime measurement of chemotactic cell motility. Biotechniques 2001;31(5):1130-1188.
76. Hu Z, Liu Q, Wang P. Cell-Based Biosensors: Principles and Applications. Artech House; 2010:150-178.

77. Park G, Choi CK, English AE, Sparer TE. Electrical impedance measurements predict cellular transformation. Cell Biol Int. 2009;33(3): 429-433.

78. Aas V, Torblå S, Andersen MH, Jensen J, Rustan AC. Electrical stimulation improves insulin responses in a human skeletal muscle cell model of hyperglycemia. Ann N Y Acad Sci. 2002;967:506-515.

79. Hu N, Zhou J, Su K, et al. An integrated label-free cell-based biosensor for simultaneously monitoring of cellular physiology multiparameter in vitro. Biomed Microdevices. 2013;15(3):473-480.

80. Large TH, Smith MW. Screening strategies for ion channel targets. In: Seethala R, Fernades PB, editors. Handbook of Drug Screening. New York: Basel; 2005:313-333.

81. Fei L, Arifuzzaman SM, Nordin AN, Spray D, Voiculescu I. Characterization of endothelial cells using electrochemical impedance spectroscopy. Proceedings of the Asia Pacific Conference on Circuits and Systems; Kuala Lumpur; December 6-9, 2010. IEEE; 2010.

82. Marimuthu M, Park C, Kim S, Choi CS. Real-time electrical measurement of L929 cellular spontaneous and synchronous oscillation. Int $J$ Nanomedicine. 2012;7:83-92.

83. Young EF. Transient impedance changes in venous endothelial monolayers as a biological radiation dosimetry response. Journal of Electrical Bioimpedance. 2012;3:61-65.

84. Young EF, Smilenov LB. Impedance-based surveillance of transient permeability changes in coronary endothelial monolayers after exposure to ionizing radiation. Radiat Res. 2011;176(4):415-424.

85. Kumar P, Miller AI, Polverini PJ. p38 MAPK mediates gamma-irradiationinduced endothelial cell apoptosis, and vascular endothelial growth factor protects endothelial cells through the phosphoinositide 3-kinase-AktBcl-2 pathway. J Biol Chem. 2004;279(41):43352-43360.

86. Han A, Frazier AB. Ion channel characterization using single cell impedance spectroscopy. Lab Chip. 2006;6(11):1412-1414.

87. Regard JB, Scheek S, Borbiev T, et al. Verge: a novel vascular early response gene. J Neurosci. 2004;24(16):4092-4103.

88. Clements RT, Minnear FL, Singer HA, Keller RS, Vincent PA. RhoA and Rho-kinase dependent and independent signals mediate TGF-beta-induced pulmonary endothelial cytoskeletal reorganization and permeability. Am J Physiol Lung Cell Mol Physiol. 2005; 288(2):L294-L306.

89. Huang F, Subbaiah PV, Holian O, et al. Lysophosphatidylcholine increases endothelial permeability: role of PKCalpha and RhoA cross talk. Am J Physiol Lung Cell Mol Physiol. 2005;289(2): L176-L185.

90. Qiao J, Huang F, Naikawadi RP, Kim KS, Said T, Lum H. Lysophosphatidylcholine impairs endothelial barrier function through the G protein-coupled receptor GPR4. Am J Physiol Lung Cell Mol Physiol. 2006;291(1):L91-L101.

91. Kim YV, Di Cello F, Hillaire CS, Kim KS. Differential Ca2+ signaling by thrombin and protease-activated receptor-1-activating peptide in human brain microvascular endothelial cells. Am J Physiol Cell Physiol. 2004;286(1):C31-C42.
International Journal of Nanomedicine

\section{Publish your work in this journal}

The International Journal of Nanomedicine is an international, peerreviewed journal focusing on the application of nanotechnology in diagnostics, therapeutics, and drug delivery systems throughou the biomedical field. This journal is indexed on PubMed Central, MedLine, CAS, SciSearch ${ }^{\circledR}$, Current Contents ${ }^{\circledR} /$ Clinical Medicine,

\section{Dovepress}

Journal Citation Reports/Science Edition, EMBase, Scopus and the Elsevier Bibliographic databases. The manuscript management system is completely online and includes a very quick and fair peer-review system, which is all easy to use. Visit http://www.dovepress.com/ testimonials.php to read real quotes from published authors. 